\title{
Teorias de Prática Social em Pesquisas em Contabilidade Gerencial: Possibilidades a partir de Pierre Bourdieu e Anthony Giddens
}

\section{Theories of Social Practice for Management Accounting Research: Possibilities from Pierre Bourdieu and Anthony Giddens}

Teorías de la Práctica Social para Investigaciones en Contabilidad Gerencial: Posibilidades a partir de Pierre Bourdieu y Anthony Giddens

\section{Rosenery Loureiro Lourenço}

Doutora em Ciências Contábeis pela Universidade Federal do Rio de Janeiro (UFRJ)

Professora da Universidade Estadual de Mato Grosso do Sul

Endereço: Rua Itiberé Vieira S/N (BR 463/Km 4,5)

Resid. Júlia Olinto Cardinal

CEP: 79900-000 - Ponta Porã, MS - Brasil

E-mail: roseneryll@gmail.com

Telefone: (67) 39266333

\section{Fernanda Filgueiras Sauerbronn}

Doutora em Administração pela EBAPE/FGV

Professora Adjunta da FACC/UFRJ

Endereço: Faculdade de Administração e Ciências Contábeis. Av. Pasteur, 250, Urca CEP: 22290-902 - Rio de Janeiro, RJ - Brasil

E-mail: fernanda.sauerbronn@facc.ufrj.br

Telefone: (21) 38735106

Artigo recebido em 27/12/2017. Revisado por pares em 15/05/2018. Reformulado em 15/06/2018. Recomendado para publicação em 15/06/2018 por Carlos Eduardo Facin Lavarda Editor-Chefe). Publicado em 30/06/2018. 


\title{
Resumo
}

Recentes estudos sobre pesquisas em contabilidade no Brasil evidenciam sua baixa diversidade e uma certa incapacidade de repensar sua orientação positivista e de perceber possíveis incompletudes, desordens, contradições e a complexidades do fenômeno contábil. Considerando esse cenário, o objetivo deste ensaio teórico bibliográfico é apontar as possibilidades de investigação fenômenos organizacionais a partir da lente de teóricos da prática, em especial, Giddens e Bourdieu. Inicialmente, o ensaio posiciona-os diante das diferentes escolas da prática social e sintetiza os modos de engajamento sob as abordagens da prática social e apresenta os elementos centrais de suas teorias. Adicionalmente, o ensaio revela que, no Brasil, estes teóricos ainda são subutilizados em contabilidade gerencial e, na sequência, traz exemplos de como algumas poucas pesquisas operacionalizaram alguns de seus conceitos. Por fim, o estudo evidencia como as teorias de Giddens e Bourdieu podem fornecer pluralidade teórica no desenvolvimento da pesquisa em contabilidade gerencial no Brasil.

Palavras-chave: Contabilidade Gerencial; Prática Social; Pierre Bourdieu; Anthony Giddens

\begin{abstract}
Recent studies on accounting research in Brazil point to its low diversity and a certain inability to rethink its positivist orientation and to perceive possible incompleteness, disorder, contradictions and the complexities of accounting phenomena. Considering this scenario, the objective of this theoretical essay is to point out the possibilities of investigating organizational phenomena from the lens of practical theorists, especially Giddens and Bourdieu. Initially, the essay positions them regarding the schools of social practice and synthesizes the modes of engagement of social practice and presents the central elements of their theories. In addition, the essay reveals that in Brazil, these theorists are still underutilized in managerial accounting and, in the sequence, it gives examples of how few researches have operationalized some of their concepts. Finally, the study shows how the theories of Giddens and Bourdieu can provide theoretical plurality in the development of research in managerial accounting in Brazil.
\end{abstract}

Keywords: Managerial Accounting; Social Practice; Critical Research; Pierre Bourdieu Anthony Giddens

\section{Resumen}

Recientes estudios sobre investigaciones en contabilidad en Brasil evidencian su baja diversidad y una cierta incapacidad de repensar su orientación positivista y de percibir posibles incompletudes, desordenes, contradicciones y complejidades del fenómeno contable. En este escenario, el objetivo de este ensayo teórico es apuntar las posibilidades de investigación fenómenos organizacionales a partir de la lente de teóricos de la práctica, en especial, de Giddens y de Bourdieu. Inicialmente, el ensayo los sitúa ante las escuelas de la práctica social y sintetiza los modos de compromiso bajo los enfoques de la práctica social y presenta los elementos centrales de sus teorías. Además, el ensayo revela que, en Brasil, estos teóricos todavía son infrautilizados en contabilidad gerencial y, a continuación, trae ejemplos de cómo algunas pocas investigaciones operacionalizarón algunos de sus conceptos. Por último, el estudio evidencia cómo las teorías de Giddens y Bourdieu pueden proporcionar pluralidad teórica en el desarrollo de la investigación en contabilidad gerencial en Brasil.

Palabras clave: Contabilidad Gerencial; Práctica Social; Investigaciones críticas; Bourdieu; Giddens 
Teorias de Prática Social em Pesquisas em Contabilidade Gerencial: Possibilidades a partir de Pierre Bourdieu e Anthony Giddens

\section{Introdução}

As tradições de pesquisa em contabilidade gerencial apresentam inicialmente, até os anos 80 , uma trajetória similar à contabilidade financeira no que se refere às abordagens teóricas adotadas, transitando de teorias normativas para positivas. Assim, de maneira concentrada, o mainstream na pesquisa em contabilidade compõe-se de lentes teóricas endossadas pela economia neoclássica (RYAN; SCAPENS; THEOBOLD, 2002). No entanto, há cerca de 40 anos a contabilidade gerencial passou a incorporar perspectivas críticas e interpretativas em seu bojo de análise (ROSLENDER, 2018).

Especialmente no que tange aos aspectos gerenciais e subjetivos das organizações, muitos autores destacam algumas limitações pertinentes às pesquisas em contabilidade gerencial que adotam uma abordagem positiva (BAKER; BETTNER, 1999; LAUGHLIN, 1995; BAXTER; CHUA, 2003). E, nesse sentido, estes mesmos autores discutem sobre a amplitude e profundidade possível para o entendimento dos fenômenos contábeis a partir de abordagens alternativas, bem como sobre a necessidade de pesquisadores em contabilidade reconhecerem a gama de alternativas possíveis para as pesquisas contábeis. Ryan, Scapens e Theobold (2002) e Roslender (2018) destacam que, no contexto internacional, revistas especializadas em abordagens mais interpretativas e críticas - por exemplo, Accounting Organizations and Society, Critical Perspectives on Accounting, Auditing and Accounting Journal - têm fortalecido uma argumentação mais crítica a partir da divulgação de artigos que abordam os fenômenos a partir de seu contexto social mais amplo.

$\mathrm{Na}$ pesquisa de fenômenos contábeis, em sua vertente gerencial, as perspectivas interpretativas e críticas avançaram especialmente em função de teorias sociais, pois estas permitiram uma reavaliação da história da contabilidade e o entendimento de sua natureza para além do modelo neoclássico do homem econômico (WICKRAMASINGHE; ALWATTAGE, 2018). Ryan, Scapens e Theobold (2002, p. 90) destacam que, embora os pesquisadores sob estas novas abordagens de pesquisa adotem diferentes pontos de vista da sociologia para delinear seus estudos, o ponto comum é que "a contabilidade é vista como socialmente construída, e não independente dos atores organizacionais, sociais e políticos". Assim Wanderley e Cullen (2011, p.16), os estudos 'alternativos' seriam mais apropriados do que estudos mainstream para o estudo de determinados fenômenos contábeis, porque esta última seria "falha em não reconhecer a contabilidade gerencial como uma pratica social".

Desse modo, para os propósitos do presente ensaio teórico-bibliográfico, as teorias sociais por nós abordadas são aquelas denominadas de 'teorias da prática' por serem um tipo de teoria social alternativa às teorias sociais clássicas e, conforme destaca Reckwitz (2002), desenham uma nova imagem do social e da ação humana. Diferentemente das teorias clássicas que consideram a ação humana 'orientada por objetivos de ação' e 'normas de ação', as teorias da prática consideram a ação humana como uma reconstrução de estruturas simbólicas de significados. Nas teorias da prática, a ordem social está incorporada em estruturas cognitivas e simbólicas coletivas e o conhecimento é compartilhado (RECKWITZ, 2002).

Dentre as inúmeras teorias da prática, nós escolhemos para o presente ensaio as perspectivas teóricas de prática social de Pierre Bourdieu e Anthony Giddens. O uso dos conceitos teóricos de Bourdieu e Giddens para compreender a realidade sob uma perspectiva crítica segue uma trajetória crescente nas pesquisas em contabilidade gerencial no contexto internacional (AHRENS; CHAPMAN, 2007; CHIAPELLO; BAKER, 2011; COOPER; HOPPER, 2007; HESFORD et al., 2007; LUFT; SHIELDS, 2007; MALSCH; GENDRO; GRAZZINI, 2011; WICKRAMASINGHE; ALWATTAGE, 2018). Ao explorar os contextos sociais e culturais, estes estudos têm lançado novas luzes sobre os fenômenos gerenciais e permitido novas interpretações para as realidades organizacionais. A título de exemplo, os 
trabalhos de Baxter e Chua (2008) e Busco e Scapens (2011) mostram como pesquisadores internacionais em contabilidade gerencial exploraram diversos conceitos de Bourdieu e Giddens.

Baxter e Chua (2008) estudaram um diretor financeiro em ação a partir da teoria da prática de Bourdieu. Os autores investigaram como este diretor financeiro incorporou sua posição, como o habitus e o estilo determinaram suas práticas, e como novos projetos estratégicos da organização foram implementados. Baxter e Chua (2008, p. 215) aplicam o conceito de campo de Bourdieu à contabilidade, sendo que "os campos são caracterizados por forças e lutas em que os agentes tentam instaurar um modo dominante de prática" e exemplificam como tais conceitos se objetivam na contabilidade gerencial: "pode haver argumentos sobre diferentes formas de custeio de produtos, que não perturbem, fundamentalmente, as noções de contabilidade como uma forma de vida, que é dirigida a manter a importância da criação de valor para os acionistas". Em Bourdieu (1990) a coerência da prática ocorre por meio do habitus, que é a forma habitual de agentes se relacionarem com o mundo social. Este habitus fornece um conjunto de "princípios de funcionamento" que permite ao agente se comportar de maneira viável em circunstâncias variadas. Como explicam Baxter e Chua (2008, p. 214), "[p]or exemplo, como contadores gerenciais, temos um habitus que nos predispõe a nos engajarmos no cálculo dos custos ou na prestação de apoio financeiro e aconselhamento em certo tipo de forma".

Busco e Scapens (2011) estudaram a natureza, os papéis e a dinâmica de mudança de um sistema de contabilidade gerencial a partir da teoria da prática de Giddens (1984). Os autores investigam a dualidade de cultura organizacional e relacionam sistemas de contabilidade e cultura para compreender como práticas de contabilidade gerencial criaram, difundiram e deram continuidade às mudanças em uma organização. Busco e Scapens (2011) consideraram a interação cognitiva e comportamental da aprendizagem para examinar a reprodução das rotinas contábeis e adicionam à teoria de Giddens contribuições advindas da psicologia cognitiva e comportamental, da antropologia e da sociologia do conhecimento para compreender o processo de mudança e a influência dos agentes na ação.

Assim, a partir da contabilidade gerencial, os autores desenvolveram um quadro interpretativo das dinâmicas cognitivas que caracterizaram a cultura organizacional e as modalidades de comportamento e estrutura, responsáveis por produção e reprodução da ordem organizacional. Ao parafrasear Giddens (1984), Busco e Scapens (2011) argumentam que os sistemas contábeis são como "provas severas de poder" que têm o potencial "para estruturar a ordem organizacional". De acordo com os autores, "ao moldar a aprendizagem organizacional, as práticas contábeis são ferramentas que os poderosos titulares, como líderes corporativos e gerentes de topo (e possivelmente também engenheiros de projetos e gerentes de finanças) usam para regular os processos de mudança" (BUSCO; SCAPENS, 2011, p. 349).

Considerando essas pesquisas e as alternativas que trazem, o objetivo do presente ensaio teórico-bibliográfico é revisitar as possibilidades para pesquisar fenômenos contábeis gerenciais no Brasil a partir da lente de teóricos da prática, em especial, Pierre Bourdieu e Anthony Giddens. Para atender ao objetivo proposto, os argumentos estão estruturados em torno de: (a) conceituar e situar prática social em termos de influências teóricas; (b) apresentar as formas possíveis de se engajar com prática social em pesquisas; (c) apresentar elementos centrais das teorias de Bourdieu e Giddens; (d) mostrar como algumas pesquisas em contabilidade no Brasil utilizaram as teorias destes teóricos da prática.

No Brasil, recentes estudos sobre pesquisas em contabilidade no Brasil evidenciam sua baixa diversidade Homero (2017b) e uma certa incapacidade de repensar sua orientação positivista e de perceber possíveis incompletudes, desordens, contradições e a complexidades do fenômeno contábil (MARTINS; ZANCHET, 2012; THEÓPHILO; IUDÍCIBUS, 2009). Da 
mesma forma, as pesquisas em contabilidade gerencial que privilegiam abordagens mais críticas e pluralistas ainda são bastante incipientes como mostram os trabalhos de Frezzati et al. (2015), Martins e Zanchet (2012), Lavarda, Borrachina e Feliu (2008) e Lourenço e Sauerbronn (2016; 2017). Nesse sentido, a relevância deste ensaio está em se somar a essas discussões sobre a pertinência de inserir pluralidade e crítica nas investigações de contabilidade gerencial e apontar aspectos inexplorados das teorias oferecidas por Bourdieu e Giddens nas pesquisas em contabilidade, evidenciando assim lacunas e possibilidades de pesquisa.

\section{Prática Social: Origem e Influências Teóricas}

A "prática" é um conceito-chave utilizado por pensadores contemporâneos como Habermas, Bourdieu, Foucault, Giddens, Schatzi, Latour, como proposta para compreender como "agência e estrutura" e "ação individual e instituições" ligam-se a "sistemas sociais, culturas e organizações" (GOLSORKHI, 2010). Esses autores são os expoentes da virada interpretativa que ocorreu a partir da década de 1970 e sedimentou na teoria social uma nova forma para compreender a ação a partir da utilização de estruturas simbólicas de significado (MACIEL; AUGUSTO, 2013)

Para Maciel e Augusto (2013, p. 161), “[a] teoria da prática, por sua vez, é considerada uma explicação desdobrada da virada interpretativa (interpretive turn) e que ainda está em seus estágios iniciais de construção e toma corpo em meio ao que se convencionou denominar virada da prática (practice turn)". Não há um sistema unificado de teoria da prática (RECKWITZ, 2002; GOLSORKHI, 2010; NICOLINI, 2012a). No entanto, estudar a prática, torna-se muito especial "por permitir que pesquisadores se envolvam em um diálogo direto com os profissionais. Estudar práticas possibilita examinar questões que são diretamente relevantes para aqueles que estão lidando com a estratégia” das organizações (GOLSORKHI, et al., 2010, p. 1).

Para Reckwitz (2002, p. 244), os teóricos práticos possuem em comum o interesse em estudar o cotidiano "mundo da vida" sob a influência de abordagem interpretativa e cultural e, de certo modo, pode se suspeitar que alguns teóricos "são dificilmente mais do que sucessores" da 'teoria da ação' fundada por Max Weber pois, como todas as teorias decorrentes desta, tratam de estruturas práticas de ação. Em função dessa orientação, em contabilidade, uma virada interpretativa nas pesquisas ocorreu no final dos anos 1970 e sustentaram-se fortemente na sociologia interpretativa de Max Weber (WICKRAMASINGHE; ALWATTAGE, 2018, p. 31).

Os teóricos da prática inserem-se em um tipo de teoria cultural que apreende a ação humana e a ordem social de uma forma diferenciada em relação às teorias sociológicas clássicas (ver Figura 1). Quanto ao termo "teoria cultural", é importante destacar, como esclarece Reckwitz (2002, p. 245), que "embora teoria da prática seja um tipo de teoria cultural, nem todos os tipos de teoria cultural são "teorias da prática"”. As outras teorias culturais delineadas pela autora são: i) Mentalismo; ii) Textualismo; iii) Intersubjetivismo. Para as teorias da prática, a ação não pode ser explicada por meio das normas ou objetivos estabelecidos, de forma que, para se apreender a ação humana e a ordem social, deve-se considerar as estruturas simbólicas compartilhadas, pois são estas que restringem os agentes e lhes permitem interpretar o mundo e se comportar de maneira correspondente a esta interpretação (RECKWITZ, 2002). 
Figura 1 - Três formas sociológicas para explicar a ação humana e a ordem social

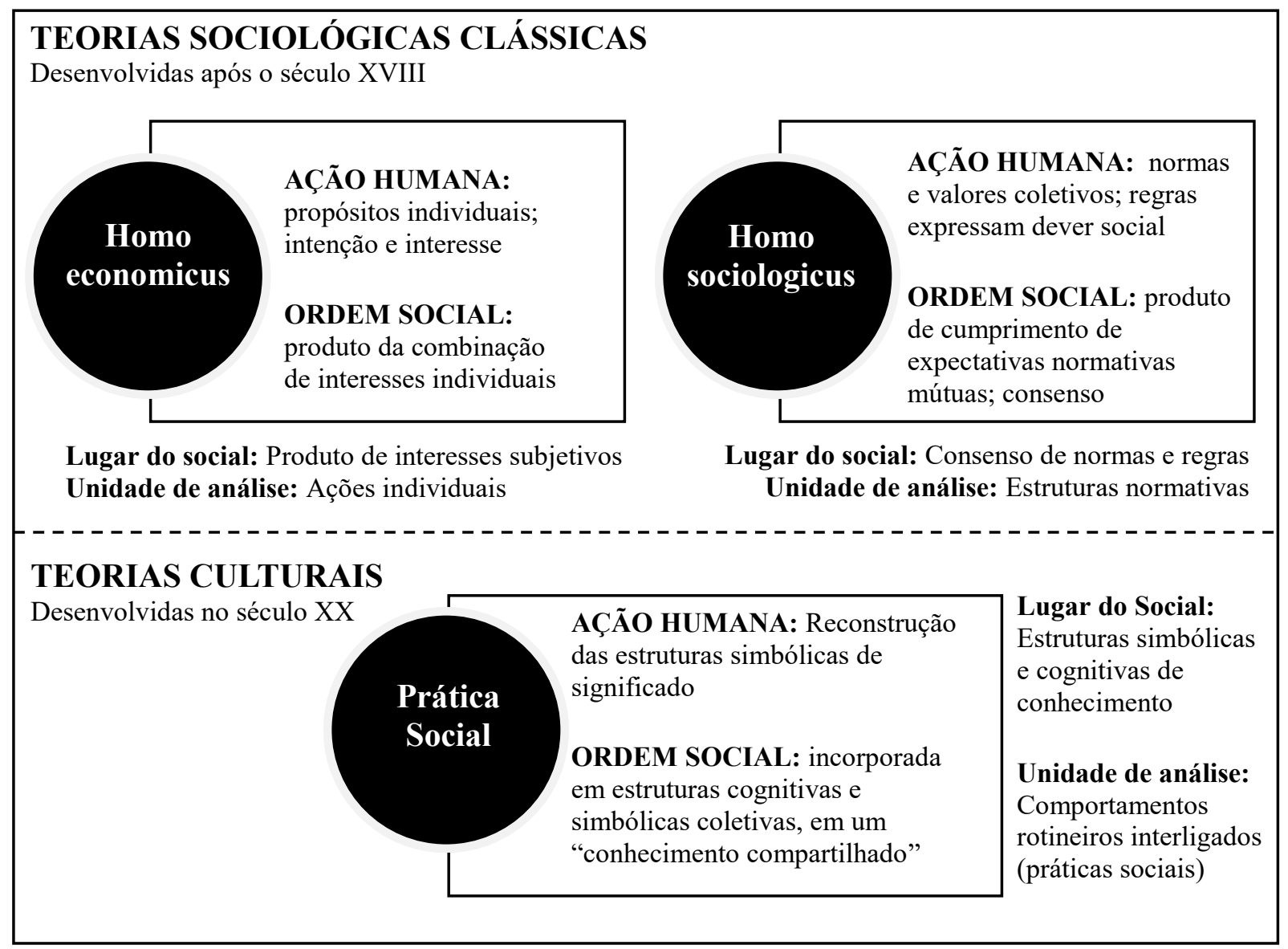

Fonte: Elaborado a partir de Reckwitz (2002)

Nessa nova imagem da ordem social - incorporada nas estruturas simbólicas coletivas - e da ação humana - reconstrução de estruturas simbólicas de significado - presente na teoria da prática, o social está nos comportamentos rotineiros interligados. Ou seja, o lugar do social para a teoria da prática não reside nas qualidades mentais, no discurso, ou na interação, mas reside simplesmente na 'prática' (RECKWITZ, 2002, p. 250). Por isso, consideramos necessário esclarecer conceitualmente os termos, 'prática', 'práticas', 'praxis' e 'rotinas', sintetizando-os no Quadro 1.

De acordo com Nicolini (2012a, p. 25), a noção ocidental de que a "boa prática deriva da aplicação de princípios gerais e eternos" tem origem em Platão, o filósofo de episteme contemplativa que colocou a prática abaixo do escopo da teoria do conhecimento e ética. No entanto, foi Aristóteles quem mostrou uma visão divergente de seu professor em relação à prática e "estabeleceu práxis como uma forma distinta de conhecer, com a sua própria lógica e legitimidade" (NICOLINI, 2012a, p. 1) na obra 'Ética a Nicômaco' e influenciou, em geral, o pensamento de Foucault e Bourdieu. Nicolini (2012a, p. 26) discorre que, para Aristóteles, o conhecimento poderia ser obtido por múltiplas e incomensuráveis formas e todas elas encerravam valor, legitimidade e critérios próprios. Enquanto Platão considerava apenas o conhecimento científico, Aristóteles fazia distinção entre "três tipos de conhecimento, ou três atividades da mente humana, ou três disposições do intelecto". 
Teorias de Prática Social em Pesquisas em Contabilidade Gerencial: Possibilidades a partir de Pierre Bourdieu e Anthony Giddens

Quadro 1 - Conceito dos termos: prática, práticas, práxis e rotinas

\begin{tabular}{|c|c|}
\hline Prática & $\begin{array}{l}\text { - Prática (Praxis, em alemão) "no singular, representa meramente um termo enfático para descrever } \\
\text { toda a ação humana (em contraste com a 'teoria' e mero pensamento)" (RECKWITZ, 2002, p. 249). }\end{array}$ \\
\hline Práticas & $\begin{array}{l}\text { - Práticas (em alemão Praktiken, no plural, ou praktik, no singular) no sentido adotado pelas } \\
\text { práticas sociais engloba a habilidosa performance humana em atividades que incluem corpo, } \\
\text { mente e emoções interligados rotineiramente. Reckwitz }(2002, \text { p. } 249) \text { destaca que "uma prática } \\
\text { (Praktik) é um tipo rotineiro do comportamento que consiste em vários elementos, interligados } \\
\text { entre si: as formas de atividades corporais, formas de atividades mentais, "coisas' e seu uso, um } \\
\text { conhecimento de fundo na forma de entendimento, know-how, estados de emoção e conhecimento } \\
\text { motivacional". } \\
\text { - "As práticas sociais são rotinas: rotinas de mover o corpo, de compreender, de querer, de usar } \\
\text { coisas, interligados em uma prática" (RECKWITZ, 2002, p. 255). }\end{array}$ \\
\hline Práxis & $\begin{array}{l}\text { - Praxis é um termo que teve mudança de sentido durante os anos e isso se deu em função da } \\
\text { interpretação feita por alguns pensadores. Inicialmente, teve o sentido de "fazer bem as coisas". } \\
\text { Esse sentido foi dado por Aristóteles, para quem práxis significava uma ação transitiva, ou seja, } \\
\text { com um fim em si mesma. Nesta perspectiva, essa ação, segundo Aristóteles poderia ser tanto } \\
\text { material quanto ideal. Mais tarde, Hegel reduziu práxis para uma noção de atividade exclusiva do } \\
\text { espírito, ou seja, práxis passou a ser entendida como algo idealista ou espiritualista, de forma que } \\
\text { a consciência seria a única forma de práxis humana e real. Uma ressignificação do termo práxis } \\
\text { foi oferecida por Marx a partir de uma abordagem do materialismo histórico, para o qual o termo } \\
\text { práxis volta a ser interpretado como material, especialmente a ação humana produtiva ou } \\
\text { transformadora. }\end{array}$ \\
\hline Rotinas & $\begin{array}{l}\text { - "Rotinas implicam em temporalidade da estrutura: práticas sociais rotineiras ocorrem na } \\
\text { sequência do tempo, em repetição; ordem social é, portanto, basicamente reprodução social. A } \\
\text { 'quebra' e 'mudança' de estruturas deve ocorrer em crises diárias de rotinas, em constelações de } \\
\text { indeterminação interpretativa e da inadequação do conhecimento com o qual o agente, na } \\
\text { realização de uma prática, é confrontado com uma 'situação"” (RECKWITZ, 2002, p. 255). }\end{array}$ \\
\hline
\end{tabular}
Fonte: Com base em Reckwitz (2002), Nicolini (2012a) e Maciel e Augusto (2013)

O primeiro tipo de conhecimento, episteme, é o conhecimento científico que apreende princípios por meio do uso da racionalidade. O segundo tipo, phronesis, é o conhecimento prático, e tem o objetivo de produzir práxis ou ação que é "informada por deliberações de valor agregado aprendido" (NICOLINI, p. 2012a, 26). Por fim, o terceiro tipo de conhecimento, techne, é aquele que "se aproxima da noção moderna de arte ou habilidade" e seu objetivo é produzir poiesis, ou seja, artefatos duráveis. Embora o filósofo destaque o conhecimento que incorpora uma preocupação com a ação prática no contexto humano, ele também considera que o conhecimento episteme está acima dos demais (idem).

$\mathrm{O}$ autor discorre que Aristóteles apresenta a sabedoria/conhecimento prático como um estado de mente preocupado com o particular em detrimento do universal. Assim, a praxis definia uma preocupação com o que era nobre, justo e bom para o homem e dizia respeito a coisas humanas possíveis de serem deliberadas. Nesse sentido, o termo era utilizado para se referir a conduta moral e a atividade política do cidadão ateniense, associando valores e ética à ação. Aristóteles estabeleceu a "incomensurabilidade parcial entre prática e teoria, e a irredutibilidade da sabedoria prática à teoria" (NICOLINI, 2012a, p. 27). Nesse sentido, o filósofo referia-se a phronesis como um conhecimento não-dedutivo e não inferencial, de forma que a práxis não poderia ser capturada de maneira apropriada por meio de regras universais e, como possui uma característica mutável, indeterminada e particular, também não poderia ser objeto de episteme (idem).

Embora Aristóteles tenha conferido uma dimensão política de ética e uma posição de conhecimento independente e legítimo à práxis, esses conceitos foram esquecidos por aproximadamente dois séculos na tradição cristã e ocidental, que adotou a ideia de conhecimento apenas resultante da vida contemplativa. Em uma reinterpretação por pensadores dos séculos XVII e XVIII, a prática foi reduzida a simples aplicação de teoria por conta do 
entendimento neoplatônico de que teoria, ética e sabedoria prática política ${ }^{\mathrm{i}}$ são distintas. Esta interpretação deslocada de Aristóteles contribuiu para que, durante muitos séculos, o conhecimento prático fosse degradado. Mas, sua importância tornou a ser recolocada a partir do século XX por Marx e Nietzsche, que redescobriram a hierarquia proposta por Aristóteles e juntamente com Heidegger e Wittgenstein contribuíram para a prática se tornar "um princípio ontológico de estar no mundo" (NICOLINI, 2012a, p. 28-29). O autor discorre ainda que, a partir da década de 1970, a tradição marxista, a tradição heideggeriana e o legado de Wittgenstein "conjuraram uma clareira na teoria social, que finalmente permitiu que a prática fosse resgatada de seu rebaixamento histórico e retornasse poderosamente para o centro das discussões." (p.41).

De acordo com Prasad (2005) e Nicolini (2012a), Anthony Giddens e Pierre Bourdieu são os principais representantes de primeira geração da praxeologia moderna. Prasad (2005) explica que Giddens e Bourdieu são considerados autores pertencentes à tradição crítica de pesquisa porque ambos foram influenciados por Marx e tratam a questão do poder seriamente, esboçando em suas teorias preocupação com estrutura, reprodução e transformação social. No entanto, conforme explica Prasad (2005), embora Anthony Giddens e Pierre Bourdieu sejam fundamentados em Marx, estes pensadores possuem diferenças interessantes e substantivas nas suas próprias posições teóricas. Enquanto Giddens trabalha em nível de microssociologia, enfatizando as escolhas individuais e a competência social no quadro de poder e focando na interpretação individual para reprodução da estrutura, Bourdieu trabalha em nível de antropologia, enfatiza a cultura como dinâmica central na estruturação e coloca seu foco nas restrições culturais sobre as escolhas individuais, a competência e a ação.

Quadro 2 - Influências teóricas sobre os estudos da prática social

\begin{tabular}{|c|c|}
\hline Marxismo & $\begin{array}{l}\text { A prática é resultante de condições históricas particulares e a prática presente é resultado } \\
\text { de práticas prévias transformadas. Nesse sentido, saber e fazer não são atividades } \\
\text { separadas e o aprendizado não consiste em uma atividade cognitiva apenas, mas em uma } \\
\text { ocorrência social. }\end{array}$ \\
\hline Fenomenologia & $\begin{array}{l}\text { O cotidiano da organização ocorre por meio de "atividades de trabalho, aprendizagem, } \\
\text { inovação, comunicação, negociação, e conflitos sobre objetivos" (BISPO, 2013, p.14). A } \\
\text { interpretação desses objetivos, a história e os significados formam a prática, de forma que } \\
\text { estes elementos não podem ser entendidos separadamente. Sujeito e objeto só têm sentido } \\
\text { enquanto construtores de significado. }\end{array}$ \\
\hline $\begin{array}{l}\text { Interacionismo } \\
\text { simbólico }\end{array}$ & $\begin{array}{l}\text { Há uma construção coletiva resultante da interação entre indivíduos e objetos. A conduta } \\
\text { humana é centrada nos significados que os fatos têm para os indivíduos. Os significados } \\
\text { são acessados pela interação humana, via linguagem e símbolos, no contexto das } \\
\text { vivências. }\end{array}$ \\
\hline $\begin{array}{l}\text { Legado de } \\
\text { Wittgenstein }\end{array}$ & $\begin{array}{l}\text { A prática social é promovida pela linguagem que, mais que transmitir informação, constrói } \\
\text { significado e sentido. Assim, participar de uma prática significa fazer parte de um jogo } \\
\text { linguístico, que é tácito e silencioso. }\end{array}$ \\
\hline $\begin{array}{l}\text { Pierre } \\
\text { Bourdieu }\end{array}$ & $\begin{array}{l}\text { A prática social deve ser refletida a partir do capital simbólico, campo social e do habitus, } \\
\text { pois é por meio do habitus que são gerados “os esquemas mentais de percepção, } \\
\text { pensamento e ação que caracterizam o comportamento dos indivíduos" (BISPO, 2013, p. } \\
\text { 16). A prática está presente na relação existente entre estruturas sociais objetivas e as } \\
\text { ações de agentes e é mediada pelo habitus que ocorre de forma tácita. "O habitus serve de } \\
\text { elo entre a estrutura (campo) e o agente (indivíduo)" (BISPO, 2013,p. 17). }\end{array}$ \\
\hline $\begin{array}{l}\text { Anthony } \\
\text { Giddens }\end{array}$ & $\begin{array}{l}\text { "As práticas são procedimentos, métodos ou técnicas que são executadas de forma hábil } \\
\text { pelos agentes sociais". Nesse sentido, o foco está em compreender "como a vida social é } \\
\text { produzida e reproduzida pela práxis", "o ponto principal está no fazer humano e não nas } \\
\text { formas de conhecer esse fazer." (BISPO, } 2013, \text { p. 17). }\end{array}$ \\
\hline
\end{tabular}

Fonte: Com base em Bispo (2013) 
Ao destacar o poder das restrições culturais sobre a agência, Bourdieu se distancia de Giddens em dois aspectos: i) na dinâmica cultural dentro do processo social, ele tem menos fé na agência individual; ii) na visão baseada em luta, ele é mais inclinado à visão de conflito na sociedade (PRASAD, 2005). O Quadro 2 sintetiza o conceito de prática social a partir suas principais influências teóricas, conforme Bispo (2013).

A forma para se buscar conhecer a 'ação humana' e pensar a 'prática cotidiana' mudou ao longo dos séculos. As mudanças no entendimento da ação se deram a partir das reflexões iniciais de Aristóteles, do Marxismo, da Fenomenologia, do interacionismo simbólico e das ideias de pensadores como Wittgenstein, Giddens e Bourdieu. Muitas destas variações no entendimento da prática cotidiana estão refletidas na forma como os pesquisadores se engajam com práticas sociais em pesquisas.

\section{Modos de Engajamento com Prática em Pesquisas}

No âmbito dos estudos organizacionais, as pesquisas baseadas em prática têm sido desenvolvidas sob a consideração de que o mundo social é melhor compreendido quando se considera as questões de historicidade e temporalidade e os fenômenos são trabalhados como 'situados' (BISPO, 2013).

Desenvolvemos na presente seção os modos de engajamento com a prática em pesquisas, a partir do trabalho de Orlikowski (2010). A autora inicia destacando que a noção de prática é utilizada na literatura gerencial para o desenvolvimento de pesquisas ao menos de três maneiras: i) prática como um fenômeno, ii) prática como uma perspectiva e, iii) prática como uma filosofia. Estas formas de desenvolver pesquisas sobre prática não são mutuamente excludentes - uma vez que muitos teóricos da prática como perspectiva também defendem a prática como filosofia - e permitem "entalhar diferentes afirmativas sobre como o poder da prática produz o mundo" (idem, p.23).

Pesquisas desenvolvidas sob o entendimento de que a prática é um fenômeno terão seu foco central sobre o que os profissionais fazem. Os acontecimentos diários da organização e a forma como ela acontece são estudados em busca de compreender como os membros da organização trabalham e, nessa busca, consideram a prática da vida organizacional mais importante do que as teorias. Para pesquisadores sob essa lente da prática existe uma distinção explícita entre práticas e teoria ou dito de outra forma, uma distinção entre o que realmente acontece e o que os pesquisadores afirmam que está acontecendo através suas representações, quadros conceituais, narrativas, modelos, proposições e teoremas. Nesse sentido, a lacuna entre o conhecimento científico e a vida real da organização é preenchido pelo aprofundamento empírico no campo (idem, p. 24).

Assim, sob o ponto de vista da prática como um fenômeno, o pesquisador está compromissado em entender a prática no dia-a-dia dos profissionais. A autora esclarece que, aqui, prática significa "noção de senso comum de atividade praticada e experiência direta". Pesquisas dessa natureza normalmente utilizam as técnicas de observação participante - com investigação em profundidade e etnografia de grupos de profissionais - e pesquisa-ação mediante parceria com profissionais e projetos - para se aproximar dos praticantes e suas práticas situadas no campo (ORLIKOWSKI, 2010).

Pesquisas desenvolvidas sob o entendimento de que a prática é uma perspectiva terão seu foco central em fenômenos sociais específicos. A autora destaca que enquanto as perspectivas tradicionais sobre estudos organizacionais privilegiam "o nível macro das relações estruturais ou o nível micro dos atributos psicológicos", a teoria da prática como uma perspectiva considera as rotinas - aqui entendidas como atividades diárias que possuem 
natureza situada e recorrente no campo, e que produzem, reforçam ou modificam as consequências estruturais - como seu objeto de análise (p.25).

Logo, sob o ponto de vista da prática como uma perspectiva, o pesquisador busca uma compreensão "teoricamente fundamentada da interação recursiva entre pessoas, atividades, artefatos e contextos"; desta forma, o pesquisador considera pessoas e tecnologia como entidades distintas, com alguma independência entre si, e que "interagem por meio de relações de mútua influência" (p. 26-27, passim). Assim, o pesquisador adota uma lente teórica prática para verificar variações específicas do fenômeno social, tais como, "a contingente e emergente natureza da atividade cotidiana, sua incorporação humana, mediação material, imersão em contextos sociopolíticos e promulgação das estruturas sociais" (idem, p. 29)

A prática social como uma perspectiva possui uma base teórica específica para analisar os fenômenos sociais e por isso passou a ser conhecida como "teorias práticas". Tem se estabelecido a partir de duas gerações: i) teóricos práticos representantes da primeira geração: Pierre Bourdieu, Michel de Certeau, Michael Foucault, Harold Garfinkel, Anthony Giddens, Charles Taylor; ii) teóricos práticos representantes da segunda geração: Sherry B. Ortner, Andrew Pickering, Andreas Reckwitz, Joseph Rouse, Theodore R. Schatzki, Bruno Latour (ORLIKOWSKI, 2010; WICKRAMASINGHE; ALWATTAGE, 2018).

As duas gerações podem ser diferenciadas a partir da ênfase e dos conceitos utilizados para analisar os fenômenos. Os estudos da primeira geração enfatizam "as ações do agente, e focam sobre como as interações e improvisações deles produzem, reproduzem e transformam a estrutura social, além disso, reconhecem as influências da estrutura e do poder sobre o corpo humano e sobre as rotinas" (ORLIKOWSKI, 2010, p. 25). Os teóricos da segunda geração utilizaram os alicerces da primeira e avançaram estendendo suas análises, conceitos, construções e entendimentos. Orlikowski (2010) destaca que, especialmente a partir das obras de Theodore Schatzki, esta geração enfatiza a prática como sendo matrizes de entendimentos e atividades humanas que são compartilhados e estão incorporados materialmente.

Pesquisas desenvolvidas sob o entendimento de que a prática é uma filosofia terão seu foco sobre o entendimento de toda a realidade social. Este modo de se engajar com a pesquisa entende a realidade social "em" e "através" das práticas. Nesse sentido, toda a vida social é constituída de práticas que são sempre dinâmicas, estão em andamento. A prática como filosofia assume uma ontologia alternativa que se situa entre o individualismo e o societismo. Trata-se do entrelaçamento ontológico, o qual postula que seres humanos e arranjos materiais não são entidades distintas e independentes entre si, mas se promulgam na prática. Nesse sentido, as relações e fronteiras entre pessoas e tecnologias não são vistas como fixas, mas entrelaçadas pelos desdobramentos das relações dinâmicas (ORLIKOWSKI, 2010).

Sob o ponto de vista da prática como uma filosofia o pesquisador considera que pessoas e tecnologias se associam de forma mutável e heterogênea e promulgam a prática como uma coprodução contínua e contingente de seu mundo sócio material compartilhado (ORLIKOWSKI, 2010, p. 27). Optou-se, nesta seção, por oferecer detalhamento dos modos de engajamento com a teoria de dois teóricos práticos que são representantes da primeira geração de estudos de prática social como uma perspectiva. Na próxima seção serão apresentados os principais conceitos utilizados por estes pensadores e, então, uma síntese a partir de artigos selecionados mostrará como os pesquisadores em contabilidade tem se apropriado de tais conceitos para desenvolver pesquisas empíricas.

\section{Elementos Centrais nas Teorias de Giddens e Bourdieu}

Estrutura e ação estão implicadas nas teorizações propostas por Giddens e Bourdieu. Ambos consideram estrutura e ação como intimamente relacionadas e construíram suas 
teorizações a partir de argumentos de Marx a respeito do fato de pessoas fazerem história (ação) em circunstâncias que não podem ser escolhidas livremente (estruturas). Para Giddens, a estrutura "são as regras e os recursos que possibilitam que as práticas se reproduzam ao longo do tempo". O foco de sua teoria são as práticas sociais que 'organizadas pelo tempo e espaço' reproduzem 'estruturas sociais' (SAUERBRONN; FARIA, 2011). Para Bourdieu, as pessoas possuem "estruturas mentais incrustadas, internalizadas - seu habitus - que permitem que elas lidem com o mundo social e o compreendam". O habitus resulta de um longo período no mundo social sob uma posição específica e ele gera as práticas que ocorrem dentro de um campo onde há competição por recursos (GIDDENS; SUTTON, 2016, p. 14-15).

Apresentamos nesta seção a prática social a partir dos elementos centrais discutidos nas teorias de Giddens e Bourdieu. Conforme sugere Prasad (2005), o entendimento de prática social sob a abordagem de Giddens requer compreender os conceitos de agência, estrutura e estruturação. Já o entendimento de prática sob a abordagem praxeológica de Bourdieu requer compreender os conceitos de habitus, campo, capital e poder simbólico. Por isto, estes foram os elementos escolhidos para a síntese que se oferece a seguir.

\subsection{Perspectiva de Prática social em Giddens}

Por mais de três décadas, Giddens tem: “(a) desafiado a sociologia clássica de Durkheim e Marx; (b) argumentado sobre a teoria social como uma força constitutiva; (c) desenvolvido uma abordagem teórica que supera o dualismo estrutura-agência; (d) examinado as circunstâncias da modernidade e seu impacto nas relações sociais e formação da identidade própria" (PRASAD, 2005, p. 184). No entanto, como destaca Prasad (2005), Giddens é mais conhecido a partir de sua teoria da estruturação que foi desenhada sob um arcabouço teórico de inspiração interpretativa e crítica em torno de estruturalismo, poder e dominação. A teoria discorre sobre o processo pelo qual as pessoas desenham a ação com base na estruturas e usamnas rotineiramente.

Para Giddens (1984) a agência humana é um fluxo contínuo e reflexivo de condução. $\mathrm{Na}$ ação humana há monitoramento reflexivo que é dependente da racionalização, um conceito descrito por ele como um processo em vez de estado de competências de agentes (ver Figura 2). Giddens defende que a agência individual é resultado de competências e habilidades sociais dos indivíduos mais do que de motivação consciente e auto interessada (SAUERBRONN; FARIA, 2011). Em seu modelo de agente, o "agir próprio envolve tratar o monitoramento reflexivo, a racionalização e a motivação da ação como conjuntos incorporados de processos". Esse agir próprio, observado em conjunto com o corpo e as mediações do mundo social, permite a compreensão da 'ação' (GIDDENS, 1984, p. 4). É nesse sentido que Giddens explica que a 'ação' não é apenas uma combinação de 'atos'.

Figura 2 - Modelo de agente de Giddens

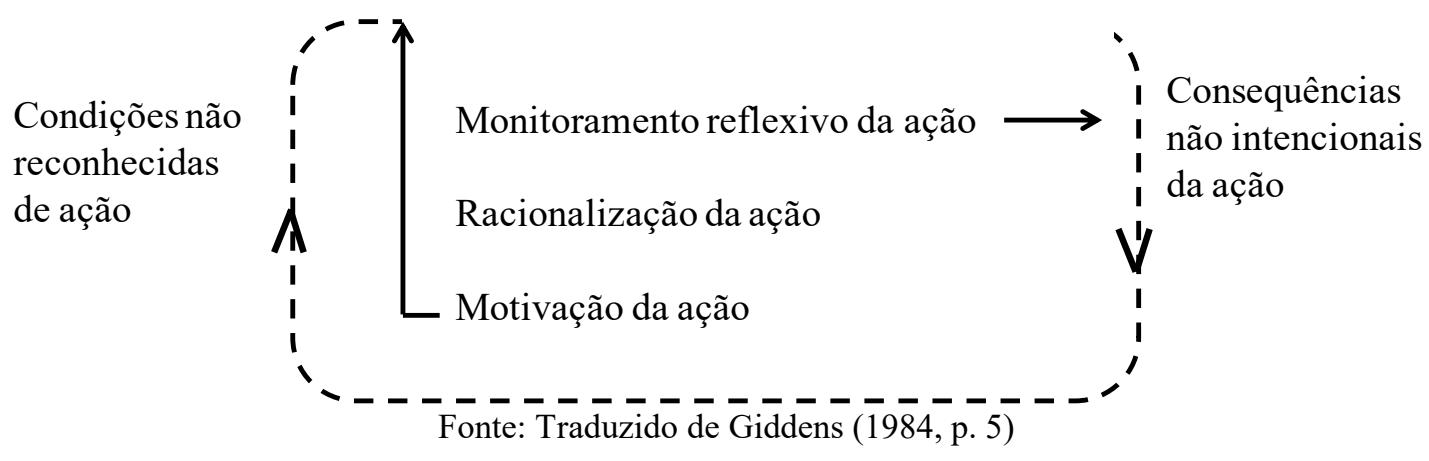


A motivação, a racionalização - intencionalidade como processo - e o monitoramento reflexivo são dimensões rotineiras da conduta humana. Os agentes monitoram suas próprias atividades e as dos outros agentes com os quais se relacionam (PRASAD, 2005). Assim, rotineiramente e sem 'barulho', eles mantêm um contínuo entendimento de suas atividades. Enquanto monitoramento reflexivo e racionalização estão ligados à continuidade da ação, a motivação diz respeito ao potencial para a ação (GIDDENS, 1984).

Giddens (1984) destaca que embora a agência humana seja definida por alguns estudiosos e filósofos em termos de intenções - fazer intencional ou não intencionalmente alguma coisa - em seu modelo, a agência humana não diz respeito a intenção consciente ou inconsciente de um agente, mas se refere a capacidade que o agente tem de fazer algo e das suas competências relacionais no contexto social. "Agência é mais do que uma questão de vontade individual e habilidade, é claro. Para Giddens, a agência é reforçada pelo controle sobre os recursos; ela é exercida através do seguimento, ou rejeição, de regras" (WHITTINGTON, 2010, p. 111). A partir dos atributos que o indivíduo possui - 'escolher sua identidade e estilo de vida pessoal', 'possuir competências sociais'- Giddens discorre que o indivíduo possui uma capacidade inata para resistir à estrutura e transformar a sociedade (PRASAD, 2005, WHITTINGTON, 2010).

De acordo com Giddens (1984, p. 16) o cerne da teoria da estruturação está nos conceitos de 'estrutura', 'sistema' e 'dualidade de estrutura' (ver Figura 3). A estrutura é considerada por Giddens (1984) tanto meio quanto resultado dos sistemas sociais. As estruturas reproduzem os sistemas no tempo-espaço a partir das interações situadas dos agentes e consistem em 'modelos' que direcionam a ação.

Para Giddens (1984), a estrutura se refere a um conjunto de regras sociais que compreende: i) normas; ii) procedimentos e convenções; iii) recursos - alocativos, autoritários, capital, tecnologia, habilidades. Para ele, todas as sociedades possuem três tipos de estruturas: (1) Estruturas de significação, que são as "regras, manuscritos, códigos e convenções que governam nossas interpretações do mundo e nossa comunicação nele"; (2) Estrutura de Dominação, que se referem aos "controles sobre recursos e inclui instituições políticas e econômicas como bancos e governo"; e (3) Estruturas de Legitimação, que dizem respeito às "instituições normativas e repositórios culturais de valores, tabus e códigos morais de conduta [como, por exemplo] igrejas, templos, corpos regulatórios, sistema judicial" (PRASAD, 2005, p. 187-188).

A agência humana ocorre a partir de três formas de interação: comunicação, poder e sanção. Estas formas de interação associam-se às dimensões estruturais de significação, dominação ou legitimação a partir de 'modalidades' (GIDDENS, 1984). A modalidade referese aos "meios pelos quais as dimensões estruturais são expressas em ação" (WHITTINGTON, 2010 , p. 112). Na estrutura de significação, a comunicação está relacionada a esquemas interpretativos. Na estrutura de dominação, o exercício do poder está relacionado a 'facilidades' assegurados pela organização como os relativos à posição ou à propriedade, por exemplo. $\mathrm{Na}$ estrutura de legitimação, a sanção tomará por base as normas de comportamento consideradas apropriadas (WHITTINGTON, 2010).

Assim, os sistemas sociais referem-se às atividades realizadas pelos agentes humanos. Eles padronizam as relações sociais, ou seja, geram as práticas sociais ao longo do tempo (GIDDENS, 1984). A estruturação para Giddens (1984) diz respeito a repetição dos sistemas sociais por meio de atividades humanas situadas e conectadas. Em contabilidade, conforme apontam Wanderley e Cullen (2011), os pesquisadores que adotam a teoria da estruturação nas pesquisas internacionais em contabilidade tendem a investigar os links entre as micro práticas cotidianas e as estruturas institucionais, em alinhamento aos trabalhos de Macintosh e Scapens (1990) e Scapens $(1990,1991)$. 
Figura 3 - A dualidade de Estrutura da Teoria da Estruturação de Giddens

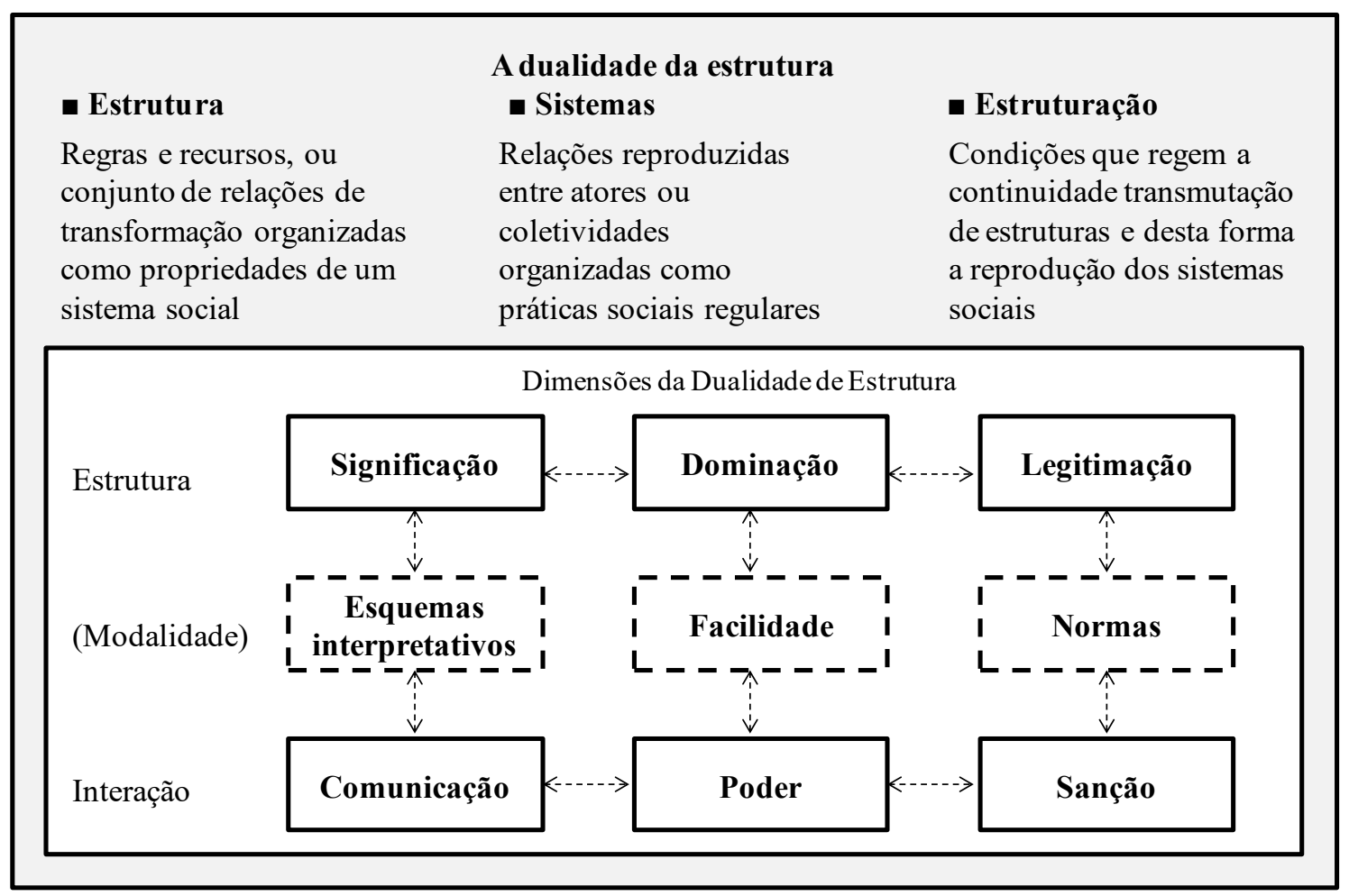

Fonte: Traduzido e adaptado de Giddens (1984, p. 25, 29)

Após, apresentados brevemente os principais conceitos de Giddens, cabe nesse momento apresentar os principais conceitos na perspectiva da prática social em Bourdieu.

\subsection{Perspectiva de Prática social em Bourdieu}

Bourdieu é considerado um teórico crítico porque foca as características culturais da vida moderna, expande as análises de capital e reprodução social, reconhece as relações de poder e enfatiza a reflexividade crítica (COOPER; HOPPER, 2007, p. 212). Assim, a teoria de Bourdieu emerge de sua insatisfação com a ênfase estrutural do marxismo e com o excessivo subjetivismo da fenomenologia e existencialismo. A praxeologia social de Bourdieu desenvolveu uma complexa visão do processo social como uma tapeçaria a partir de tópicos conceituais de Durkheim, Weber e Marx (PRASAD, 2005).

Em seus escritos sobre a prática social Bourdieu conecta estrutura e agência por meio da ideia de contínua luta cultural entre diferentes grupos e sobre diferentes fontes de recursos (PRASAD, 2005, p. 194). Como discorre Prasad (2005), a ênfase da dinâmica cultural dentro dos processos sociais permite que Bourdieu tenha menos fé na agência individual do que tem a teoria da estruturação de Giddens, de maneira que, no pensamento de Bourdieu, as restrições culturais restringem a ação do indivíduo.

O mundo social - as relações entre atores sociais e a sociedade - é articulado dialeticamente por uma abordagem epistemológica que Bourdieu chama de 'conhecimento praxeológico', uma forma de conhecimento intermediário entre o conhecimento objetivista e o fenomenológico. Nesse sentido, Bourdieu (1983, p. 47) explica que o conhecimento teórico praxeológico considera as relações objetivas construídas pelo método objetivista e também as relações dialéticas entre estruturas objetivas e disposições estruturadas do método subjetivista. 
A abordagem praxeológica de Bourdieu difere da fenomenologia porque seu intento não é simplesmente rejeitar por completo o conhecimento objetivista, mas ultrapassar seus limites. Segundo Bourdieu (1983, p. 49), “[o] conhecimento praxeológico não anula as aquisições do conhecimento objetivista, mas as conserva e ultrapassa, integrando o que esse conhecimento teve que excluir para obtê-las". Assim, Bourdieu torna a construção do objeto de pesquisa como importante "front end" e a reflexividade como importante "back end" (EVERETT, 2018, p. 113).

Os conceitos centrais de sua teoria giram em torno de campo, poder e capital, habitus e violência simbólica, que foram empregados para interpretar a contabilidade e outras práticas calculativas como particulares esquemas de dominação e violência simbólicos específicos do campo (WICKRAMASINGHE; ALWATTAGE, 2018, p. 24). Primeiro, ao tratar do conceito de campo, Bourdieu (2005, p. 150) salienta que: "[e]m termos analíticos, um campo pode ser definido como uma rede ou uma configuração de relações objetivas entre posições. Estas posições são objetivamente definidas na sua existência e nas determinações que impõem aos seus ocupantes, agentes ou instituições". Portanto, o campo é, simplesmente, qualquer arena de disputa simbólica e material na qual alguns atores possuem mais poderes do que outros, não sendo necessariamente uma organização ou instituição (EVERETT, 2018, p. 114).

Segundo, no pensamento de Bourdieu, o conceito de capital está intimamente ligado ao conceito de campo, pois deriva das disputas de poder possuem variadas formas. $\mathrm{Na}$ abordagem do autor o que organiza o campo é o quadro de conflitos. Nesse sentido, o campo é uma arena de forças competitivas. Ou seja, é composto por espaços hierárquicos nos quais os agentes lutam constantemente para manter ou ganhar posição social através dos capitais (econômico, cultural e simbólico) que possuem. Anand e Jones (2008, p. 1038) asseveram que "[a] abordagem de Bourdieu sugere que além de facilitar as estruturas de dominação em hierarquias sociais, mecanismos de configuração de campo devem também [...] permitir a transformação do capital dentro de um campo."

Todo campo tem grupos dominados e dominadores. Campos não são espaços estáticos e possuem jogos específicos, pois as tensões e lutas constantes que existem dentro de um campo de poder se dão em torno de recursos materiais, recursos simbólicos e mecanismos de reprodução (BOURDIEU, 1984, 2005). Para o autor, o sistema simbólico - poder simbólico de uma sociedade legitima a dominação por meio de uma imposição tácita do que é uma 'definição correta' de mundo social. Segundo ele, "grupos sociais se envolvem em disputas sobre o espaço simbólico empregando os diferentes tipos de capitais que possuem, para posicionarem-se no campo institucional" (PRASAD, 2005, p. 195). Logo,

Dinheiro é uma forma de capital econômico; uma credencial é uma forma de capital cultural, assim como o conhecimento; e a participação em uma rede de relações provê capital social. Quando uma forma de capital é considerada legítima, seu possuidor acumula a mais persistente forma, o capital simbólico. (EVERETT, 2018, p. 114)

Terceiro conceito fundamental é o habitus que, de acordo com Bourdieu (1996), pode ser individual ou coletivo, é um dos conceitos-chave em sua teoria praxeológica. Os habitus são diferentes e separados das estruturas. Emergem a partir da submersão do pesquisador em uma história empírica, situada em termos espaço-temporais. Quando individuais, os habitus não são separados da individualidade orgânica; quando coletivos, estão presentes "não na singularidade das naturezas, mas nas particularidades de histórias coletivas diferentes" (BOURDIEU, 1996, p. 15). Assim,

[a]s estruturas constitutivas de um tipo particular de meio, ou seja, as condições materiais de existência características de uma condição de classe, que podem ser apreendidas empiricamente sob a forma de regularidades associadas a um meio socialmente estruturado, produzem habitus. (BOURDIEU, 1983, p. 61). 
Ao conceituar o habitus como um princípio, Bourdieu $(1983,1990)$ deixa claro que se trata de um elemento invisível que orienta a ação, mas que tem um caráter dinâmico e não determinístico e é expresso nas possibilidades de improvisação do agente, "que não pressupõe um domínio consciente do fim ou o domínio de uma necessária operação para atingi-lo" (BOURDIEU, 1990, p. 53). O habitus gera e estrutura tanto as práticas quanto as representações sociais. Estas representações podem ser 'reguladas' e 'regulares' sem que necessariamente sejam resultado da obediência às regras ou resultado "da ação organizadora de um regente" (BOURDIEU, 1983, p. 63).

Em sua análise sobre os textos de Pierre Bourdieu, Ortiz (1983, p.15) destaca que Bourdieu reinterpretou o sentido de habitus, que era visto pela escolástica como um modus operandi, isto é, 'como disposição estável para se operar em determinada direção'. Agora, o habitus assume a pressuposição de um conjunto de "esquemas generativos" que dirigem a escolha, se reporta a um sistema de classificação que é anterior à ação.

Entretanto, cabe destacar que Bourdieu (1983, p. 64) rejeita a prática como reação mecânica e determinada por condições antecedentes e reduzidas a "esquemas préestabelecidos", "modelos", "normas" ou papéis", pois isto ignoraria o habitus, que é produto de diferentes condições de existência às quais o agente está sujeito. Em uma dada situação, "a prática é, ao mesmo tempo, necessária e relativamente autônoma [...] porque ela é o produto da relação dialética entre uma situação e um habitus" (BOURDIEU, 1983, p. 65). Assim, conforme explica Bourdieu (1983, p. 76) "enquanto produto da história, o habitus produz práticas, individuais e coletivas, produz história, portanto, em conformidade com os esquemas engendrados pela história".

Em síntese, para Bourdieu (1983, p. 65) as práticas só podem ser explicadas, se colocadas em relação "a estrutura objetiva que define as condições sociais de produção do habitus [...] com as condições do exercício desse habitus". Bourdieu (1984, p. 101) relaciona ainda as práticas à condição de classe e à condição social que permitem entender a vida social dos agentes. Prática e posição social 'nutrem-se' mutuamente.

Percorridos os principais conceitos da teoria da prática social de Bourdieu, a próxima seção abordará as pesquisas em contabilidade publicadas em periódicos nacionais com o intuito de mostrar como os pesquisadores têm utilizado as teorias de Giddens e Bourdieu.

\section{Um olhar no que se fez para projetar o que fazer}

Essa seção, ao considerar o argumento de Frezatti et al. (2015), entende que olhar para o que se tem produzido do outro lado do mundo não deve implicar em 'simplesmente copiar e reproduzir', mas pensar criticamente o que pode ser relevante para entender o contexto nacional a partir de lentes mais pluralistas. Nesse sentido, a seção apresenta um breve panorama de pesquisas em contabilidade publicadas em periódicos nacionais com o intuito de mostrar como os pesquisadores têm utilizado as teorias de Giddens e Bourdieu e discorrer sobre gaps e oportunidades para pesquisadores em contabilidade gerencial avançarem em direção aos aprofundamentos teóricos e metodológicos propostos por estes dois teóricos da prática.

A seleção dos textos aqui discutidos se deu a partir de uma busca nas bases 'Spell', 'SciELO' e 'Periódicos Capes', no mês de outubro de 2017, usando-se a combinação das palavras chaves 'Bourdieu e contabilidade' ou 'Giddens e contabilidade' como critério de busca em cada um dessas bases. Desta forma, está fora da síntese analítica apresentada nos quadros que se seguem, aquilo que se tem produzido no Brasil por meio de dissertações e teses oriundas dos programas de pós-graduação em contabilidade, que oferecem cursos de mestrado e doutorado, os quais somam, segundo os dados da avaliação quadrienal 2017 disponibilizados pela Capes, cinco programas de mestrado profissional, 12 programas de mestrado acadêmico, 
15 programas de mestrado/doutorado (CAPES, 2017). Também não foram analisados os artigos e contabilidade que apenas mencionavam "Bourdieu" ou "Giddens", mas que não sustentavam o estudo em seus quadros teóricos e analíticos.

As Figuras 4 e 5 caracterizam os artigos encontrados nas referidas bases e que tratam dos fenômenos contábeis à luz das teorias destes práticos. A quantidade de artigos encontrados permite observar que a utilização das teorias de Pierre Bourdieu e Anthony Giddens nas pesquisas em contabilidade no Brasil ainda é incipiente, o que sugere que há muito para se explorar no que concerne aos aspectos teóricos e metodológicos oferecidos por estes teóricos de prática social.

Figura 4 - Conceitos da Teoria de Bourdieu utilizados nos artigos em contabilidade

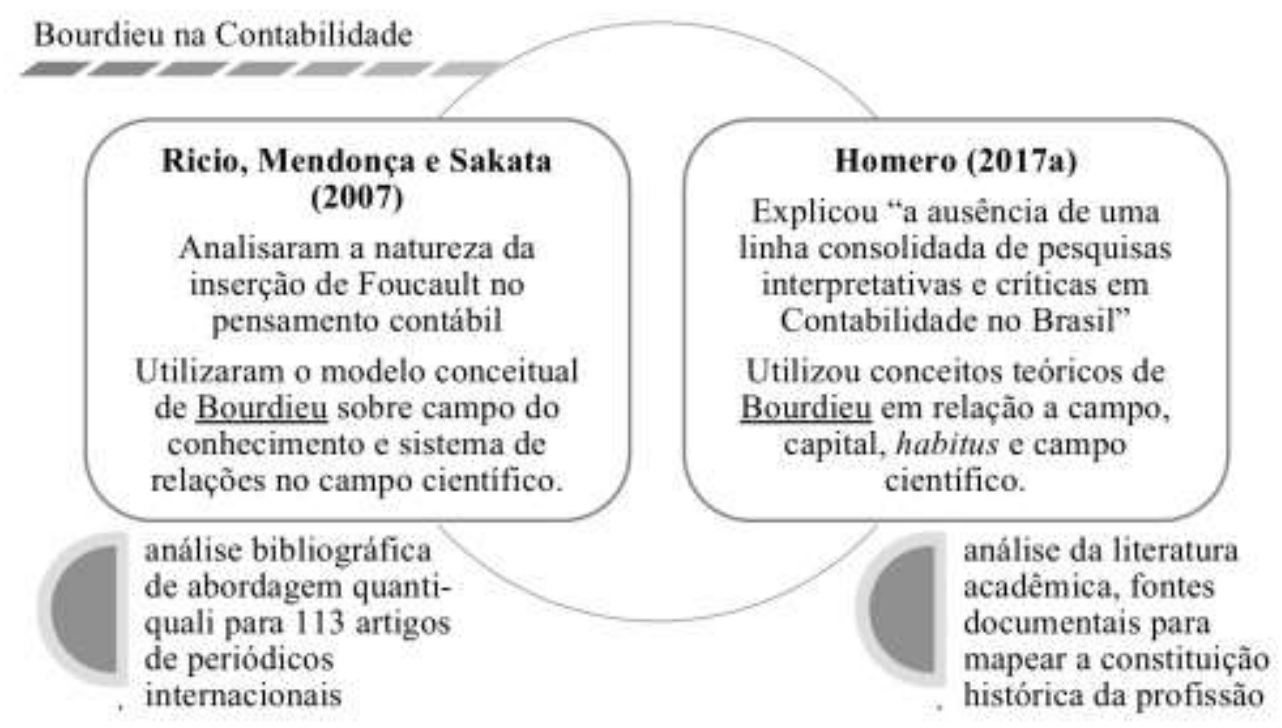

Fonte: Dados da pesquisa

Iniciando pelo que se encontrou sobre Bourdieu, os dois primeiros artigos não estão no âmbito da contabilidade gerencial. Em vez disso, os textos tratam da contabilidade de forma geral e não são estudos que analisam organizações brasileiras, mas constroem: i) uma análise de contornos pós-positivista das publicações internacionais sobre Foucault na contabilidade e, ii) uma análise da constituição do campo científico da contabilidade brasileira para discutir a ausência de abordagens interpretativas e críticas na pesquisa.

Riccio, Mendonça e Sakata (2007) realizam uma análise bibliográfica de abordagem quanti-qualitativa para 113 artigos de periódicos internacionais. $\mathrm{Na}$ parte quantitativa da pesquisa, os autores utilizam bibliometria e Lei de Lotka; na parte qualitativa, eles classificam os artigos analisados quanto aos paradigmas, estratégias e tipos de análise propostas por Denzin e Lincoln (2000). Riccio, Mendonça e Sakata (2007) se propõem a explorar a contabilidade a partir do conceito de 'campo' de Pierre Bourdieu, mas consideram apenas as questões que estão postas objetivamente. Os aspectos subjetivos dos quais Bourdieu trata em sua praxeologia não são explorados pelos autores no artigo.

Ao aplicar os conceitos de Bourdieu para investigar a inserção do pensamento de Foucault na pesquisa contábil, Riccio, Mendonça e Sakata (2007) concluíram que as ideias de Foucault têm influência significativa na pesquisa contábil internacional e que, quanto aos paradigmas de pesquisa utilizados, há forte predominância de estudos teóricos, seguido de estudos históricos; as estratégias de pesquisa predominantes são os estudos bibliográficos seguidos de estudos de caso; o tipo de análise mais utilizada é a análise crítica; os periódicos 
com mais publicações sobre Foucault e com uso de análise crítica estão concentrados na Europa; e a contabilidade gerencial é o tema predominante de pesquisa. O ponto de vista ontológico de Bourdieu privilegia uma praxeologia que não despreza a sinergia objetivosubjetivo. Pode-se dizer que Riccio, Mendonça e Sakata (2007) reconhecem essa lacuna em relação aos aspectos subjetivos dos agentes em seu trabalho quando citam nas conclusões que certas respostas concernentes ao campo somente seriam alcançadas se os autores dos artigos tivessem sido ouvidos de forma direta. Portanto, os autores não analisam o jogo de poder os capitais ou habitus característicos do campo.

Homero (2017a) se propõe a explorar a constituição do campo científico da contabilidade brasileira considerando os contornos teóricos apresentados por Bourdieu. $\mathrm{O}$ autor discorre sobre disputas no campo em torno da autoridade e legitimidade científica e em torno das disputas de escolas italiana e norte-americana para treinamento profissional, o que refletiu nos cursos de pós-graduação. Também aponta, entre outros aspectos, como a profissão contábil se estabeleceu a partir da escola de comércio, da legislação e como o Conselho de Classe Contábil foi pivotal no estabelecimento de critérios profissionais e acadêmicos. Homero (2017a) aplica uma lógica abdutiva para conduzir a investigação e considera tanto documentos como sua experiência pessoal no campo para refletir sobre seu problema de pesquisa. $\mathrm{O}$ emprego de reflexividade para compreensão das práticas sociais e de pesquisa é um aspecto que Bourdieu $(1984,1990)$ apresenta como fundamental na realização de pesquisa social. Ao aplicar os conceitos de Bourdieu para explicar a ausência de estudos interpretativos e críticos na contabilidade, Homero (2017a) concluiu que a pesquisa contábil brasileira, caracteristicamente positivista e de pouca diversidade, é pouco desenvolvida naquelas abordagens porque o campo acadêmico de contabilidade tem baixa autonomia em relação ao campo profissional.

Encontrar nessas bases apenas dois artigos de contabilidade relacionados à teoria de Bourdieu é um fato que corrobora com a constatação feita por Malsch, Gendron e Grazzini (2011) no contexto internacional. Embora Pierre Bourdieu possua grande influência nas pesquisas internacionais de contabilidade - Bourdieu é o terceiro teórico francês mais citado, Foucault e Latour são os dois primeiros (CHIAPELLO; BAKER, 2011), Malsch, Gendron e Grazzini (2011, p. 194) destacam que as pesquisas em contabilidade ainda não exploram de forma significativa a sua teoria. Segundo estes autores, Bourdieu é subutilizado nos estudos gerenciais e em boa parte das pesquisas há "uma lacuna entre a visão de Bourdieu da pesquisa acadêmica como um apoio a causas políticas e sociais debatidas na arena pública versus uma abordagem mais desapaixonada para pesquisar". Ao considerar os dois estudos apresentados acima, Riccio, Mendonça e Sakata (2007) e Homero (2017), é possível observar que os artigos usaram prioritariamente fontes bibliográficas e documentais. Estudos futuros poderiam considerar a análise dos aspectos subjetivos presentes na teoria da prática de Bourdieu e, desta forma, investigar mais profundamente como o habitus e sua relação dinâmica com o campo e os capitais geram as práticas sociais em fenômenos da área contábil. Estudos de inspiração etnográfica, e que permitam confrontar os elementos presentes em documentos e bibliografias com entrevistas e observações, podem permitir um aprofundamento na análise das relações discutidas por Bourdieu.

No Brasil, a área de estudos organizacionais, por exemplo, usa os conceitos de Bourdieu para investigar os contextos em que as organizações estão imersas e investigar como os aspectos de agência, controle e tomada de decisões se entrelaçam. Estes estudos são importantes ao se pensar em contabilidade gerencial no Brasil, pois podem oferecer insights para que os pesquisadores estruturem suas análises sobre os fenômenos contábeis gerenciais. Além disso, estes estudos podem auxiliar na compreensão de como os conceitos de Bourdieu foram operacionalizados dentro do contexto brasileiro. Silberman, Pacheco e Fonseca (2015), por exemplo, identificaram o poder simbólico em feiras orgânicas do Rio de Janeiro. Para 
operacionalizar o poder simbólico de Bourdieu as autoras adicionaram os elementos da Estratégica de Poder de Mintzberg e avaliaram o poder micro e macro a partir da comparação das feiras com organizações influenciáveis por atores internos e externos. O sistema simbólico vigente e o poder simbólico praticado pelos agentes sociais no contexto das feiras foram identificados a partir da crença de legitimidade dos produtos. De acordo com as autoras, o poder simbólico nas feiras cariocas está organizado "sob a forma de coalizões e redes de poder" e este poder simbólico exercido por feirantes e por entidades que controlam e avaliam a conformidade orgânica pode influenciar a legitimidade dos produtos vendidos (SILBERMAN; PACHECO; FONSECA, 2015).

Outro exemplo da utilização de Bourdieu para analisar empresas brasileiras é o estudo de Queiroz (2008) que buscou compreender o universo de empresas familiares sob o entendimento de que estas adotam 'uma lógica própria para administrar' não necessariamente convergente com a lógica econômica. Nesse sentido, a autora usou a teoria de campos sociais de Bourdieu para explorar como funciona nas famílias uma lógica econômica às avessas e qual é o papel das trocas simbólicas existentes nas relações sociais destes tipos de organizações. $\mathrm{O}$ estudo realizado em quatro empresas familiares discorreu como estas empresas familiares se constituem em um campo de poder e como a lógica econômica e a lógica familiar (que privilegia os interesses da família) funcionam na prática.

Em seu estudo Queiroz (2008) argumenta, a partir da lente de Bourdieu, como é possível observar as complexas relações de poder e a dominação estabelecidas nestas empresas considerando as trocas simbólicas e como uma lógica própria de administração surge de duas lógicas distintas e conflitantes que se alternam e se sobrepõem continuamente. De acordo com Queiroz (2008), a profissionalização é a principal característica que distingue as pequenas e médias empresas familiares entre si. Nesse sentido, "empresas menos profissionalizadas tendem a privilegiar os interesses da família em detrimento dos interesses da empresa, ao passo que as mais profissionalizadas conseguem separar melhor os assuntos relativos à empresa e a família" (QUEIROZ, 2008, p. 15).

Os estudos de Silberman, Pacheco e Fonseca (2015) e Queiroz (2008) podem servir de inspiração para pesquisadores em contabilidade gerencial no Brasil repensarem aspectos de poder nas organizações e elaborarem suas questões de pesquisa em torno da inserção da contabilidade no campo de poder sob a perspectiva de Bourdieu. Analisar a contabilidade gerencial de empresas brasileiras considerando seu contexto social e histórico é relevante, pois esse tipo de análise permite compreender, como destacam Luft e Shields (2007, p. 43), como práticas de contabilidade gerencial moldam e são moldadas pela subjetividade humana, como ocultam o poder e como dão visibilidade aos indivíduos dentro das organizações.

Além destas pesquisas, o artigo de Jayasinghe e Wickramasinghe (2011) pode servir de inspiração aos pesquisadores em contabilidade gerencial no Brasil para operacionalizar e organizar a interação dos conceitos de habitus, campo e capital propostos por Bourdieu. Estes autores identificaram lógicas de campo concorrentes, os discursos de desenvolvimento contábil, avaliação de desempenho, governança e controle, accountability, e os mecanismos de reprodução da pobreza rural.

Para compreender o gap e explorar as possibilidades, além de considerar o que já foi investigado em contabilidade e como pesquisas na área de estudos organizacionais podem inspirar o desenvolvimento de novas investigações empíricas sob a lente de Bourdieu, é importante que os pesquisadores em contabilidade gerencial prestem atenção em um aspecto fundamental: a unidade teórica básica da teoria de Bourdieu. Embora a utilização de Bourdieu esteja crescendo nos estudos organizacionais e os conceitos mais frequentemente utilizados do autor sejam "capital, habitus, campo, práticas sociais, dualidade de estrutura e agência, teoria da prática, lógica da prática e poder" (SIEWEKE, 2014), os conceitos de campo, habitus e 
capital não são trabalhados de forma fragmentada na teoria de Bourdieu. Disso decorre que esses três elementos existem como uma unidade teórica para a compreensão das práticas. Por esta razão, não deveriam ser analisados separadamente nas pesquisas empíricas (TOWNLEY, 2014, p. 59).

Passando agora para o que se encontrou nessas bases em termos de pesquisas em contabilidade no Brasil sob a teoria de Giddens, é possível observar, como sugere a Figura 5, que os pesquisadores em contabilidade gerencial trazem discussões mais voltada para as práticas nas organizações, diferente do que se constatou em relação a utilização de Bourdieu na Figura 4, onde os pesquisadores buscaram compreensões sobre contornos da pesquisa contábil. Agora, sob a perspectiva de Giddens aparecem quatro artigos. A análise dos artigos apresentados na Figura 5 evidencia que a teoria prática de Giddens está sendo utilizada nas pesquisas em contabilidade gerencial para conduzir investigações em torno do tema mudança nos sistemas contábeis gerenciais: orçamentos, medidas de desempenho; e nas normas de contabilidade.

Os estudos apresentados na Figura 5 chamam a atenção para um aspecto interessante na operacionalização dos conceitos de Giddens. Esse aspecto diz respeito à utilização da teoria da estruturação somada à outras perspectivas teóricas que possam oferecer mais concretude aos conceitos abstratos de Giddens e aderência na operacionalização de níveis macro e micro, conforme mostra o estudo de caso interpretativo de Wanderley e Cullen (2012).

Figura 5 - Conceitos da Teoria de Giddens utilizados nos artigos em contabilidade

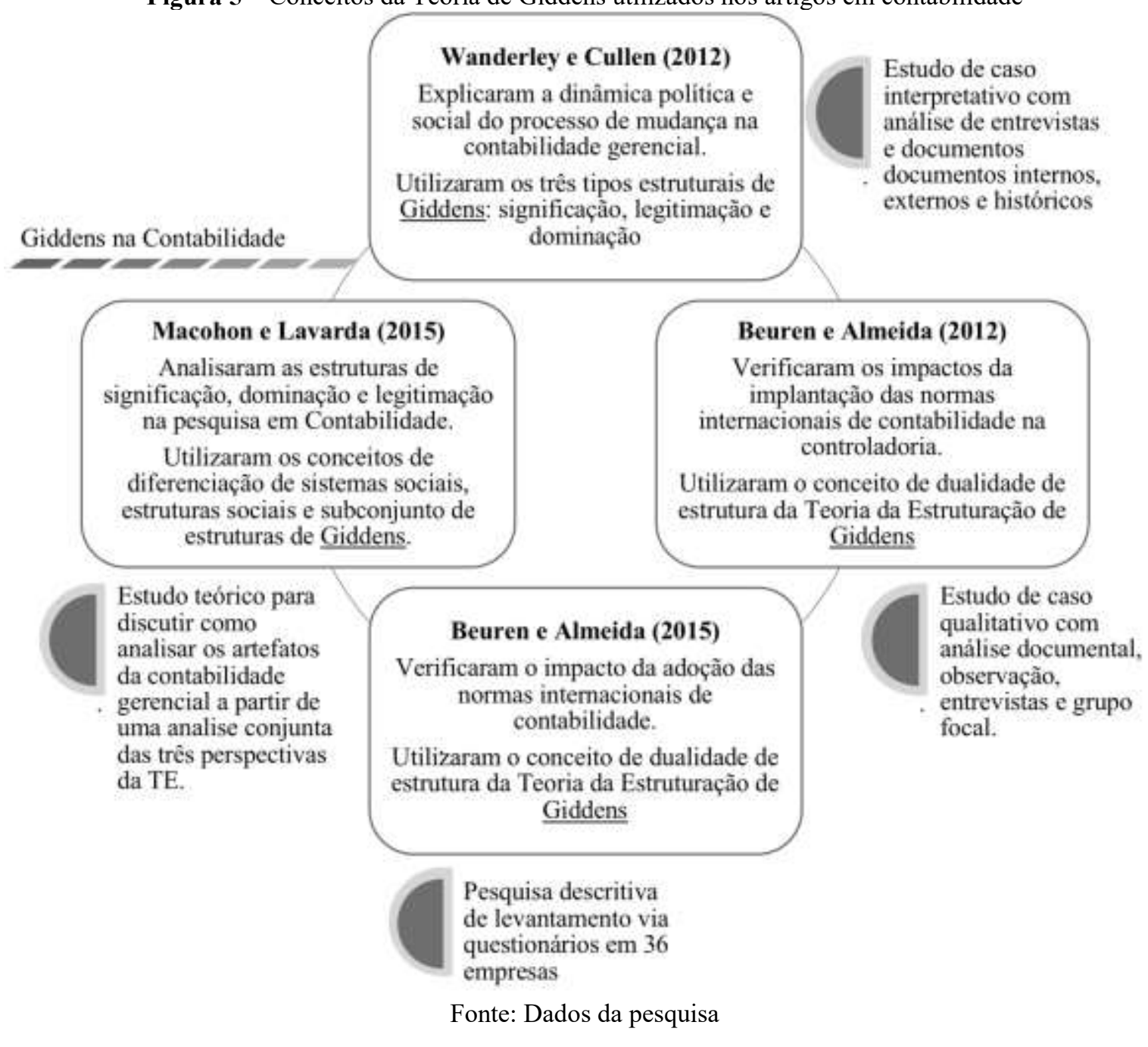


Wanderley e Cullen (2012) utilizaram os construtos propostos por Dillard, Rigsby et al. (2004) para articular e compreender os três níveis do sistema social e político: a) eixos de tensão de Weber; b) teoria de estruturação de Giddens, com os conceitos de legitimação, significação e estruturas de dominação. Os autores consideraram que os tipos estruturais da teoria da estruturação de Giddens, significação, legitimação e dominação, "coincidem com os três eixos de tensão: as estruturas de significação como análogas ao eixo representacional; as estruturas de legitimação representando o eixo de racionalidade; e as estruturas de dominação representando o eixo do poder" (WANDERLEY; CULLEN, 2012, p. 165). Os autores organizaram a análise do caso de modo a evidenciar as estruturas sociais da organização, enquadrando para cada nível, político e econômico, campo organizacional, intraorganizacional, as características estruturais pré e pós-privatização relativas a cada uma das estruturas, legitimação, significação, dominação. Assim, concluem que as profundas mudanças nos sistemas gerenciais de orçamento, de medida de desempenho e na forma de usar a informação gerencial na empresa analisada "foram iniciadas e sustentadas por mudanças concomitantes nos fundamentos legitimadores, estruturas de significação e perspectivas de dominação e não podem ser compreendidas adequadamente sem considerar essas três dimensões interrelacionadas e as influências provenientes dos níveis do campo organizacional e da sociedade" (p. 171).

No contexto internacional essa tendência de considerar uma combinação de perspectivas teóricas para compreender a aplicação empírica da estruturação de Giddens pode ser observada no estudo de Coad e Herbert (2009), por exemplo. Estes autores desenvolvem um estudo empírico para testar uma contribuição recente de Stones (2005) para a teoria da estruturação de Giddens em contabilidade gerencial. Stones (2005) defende um afastamento dos conceitos abstratos de Giddens e sugere o conceito de práticas de posição em combinação com uma estrutura quadripartite. Coad e Herbert (2009, p. 177) concluem que a proposta de Stones (2005) permite focar "a conduta estratégica dos agentes, a importância do poder na interação social e uma pluralidade de estruturas e teorias de ação [...] a fenomenologia, a hermenêutica e as práticas dos agentes", mas não oferece ideias diretas sobre "os processos de reprodução, aprendizado e mudança na contabilidade gerencial". Desta forma, sugerem que tal limitação seja superada pela utilização flexível da teoria da estruturação em adição a outras perspectivas teóricas que centralizem dependência, contradição e praxis.

A lente de Giddens para compreender o processo de implantação de normas de contabilidade no Brasil pode ser vista nos estudos de Beuren e Almeida $(2012,2015)$ com foco no impacto da adoção de normas internacionais, primeiro utilizando um estudo de caso e depois adotando uma estratégia de levantamento. No primeiro estudo, Beuren e Almeida (2012) desenvolveram a pesquisa tomando por base teórica a Dualidade de Estrutura conforme proposta por Giddens $(1979 ; 2003)$ e utilizaram os aspectos metodológicos presentes em Macintosh e Scapens (1991). As autoras consideraram a teoria da estruturação para enquadrar metodologicamente a empresa em dois níveis: a análise institucional, com foco nas estruturas, e a análise da conduta estratégica, com foco na agência humana. Com base nestes conceitos de Giddens, as autoras consideraram os níveis complementares pelo princípio da dualidade da estrutura e apresentaram o sistema social e as estruturas pelas quais o controller e os outros agentes orientam suas ações diárias. Para analisar a dualidade de estrutura, as autoras utilizaram 12 perguntas para verificar significação/comunicação, dominação/poder e legitimação/sanção. $\mathrm{Na}$ análise do estudo de caso Beuren e Almeida (2012, p. 653) concluíram que a dualidade de estrutura nos termos apresentados por Giddens ocorreu na empresa analisada, de forma que "o processo de implantação das normas internacionais de contabilidade impactou a estrutura da área organizacional controladoria, por meio de novas atividades, discussões e mudanças nos 
processos e controles, além da interação dos agentes, por meio de comunicação e capacidades, permitindo a produção e a reprodução dessa área" (BEUREN; ALMEIDA, 2012, p. 653).

No segundo estudo, Beuren e Almeida (2015) continuaram desenhando sobre a Dualidade de Estrutura conforme proposta por Giddens $(1979 ; 2003)$ e incrementaram seus aspectos metodológicos utilizando os insights dos estudos de Macintosh e Scapens (1990, 1991), Barrachina (2001), Junquilho (2003) e Busco (2009). As autoras elaboraram seis hipóteses com base nos pilares da teoria da estruturação e desenvolveram um esquema de análise em três etapas no qual a estruturação da controladoria foi evidenciada a partir do sistema social, da análise institucional e da análise da conduta. De modo similar à pesquisa anterior, na pesquisa de levantamento, Beuren e Almeida (2015, p. 331) concluíram que a adoção das normas internacionais de contabilidade impactou a área da controladoria, "a dualidade da estrutura na área organizacional da controladoria com a adoção das normas internacionais, com a estrutura (significação, dominação e legitimação), influenciando a ação dos agentes (comunicação, poder e sanção) e a ação influenciando a estrutura". As autoras constataram correlações significativas entre os pilares de significação, legitimação e dominação: "[t]ais correlações evidenciam a transição dos estágios, cognitivo, regulativo e normativo durante o processo de convergência" (BEUREN; ALMEIDA, 2015, p. 331)

Um outro aspecto que chama à atenção ao olhar para a Figura 5 é que há lacunas importantes a serem preenchidas no que se refere a pesquisas empíricas baseadas na teoria da estruturação. Neste sentido, Macohon e Lavarda (2015) oferecem uma agenda de pesquisa que pode permitir um aprofundamento da contabilidade gerencial no Brasil, a partir do desenvolvimento de pesquisas que explorem as possibilidades apontadas. Nesse estudo teórico os autores buscaram discutir como analisar os artefatos da contabilidade gerencial a partir de uma análise conjunta das três perspectivas da Teoria da Estruturação. Os autores argumentam que "a Tríade de Giddens pode condicionar a estruturação de artefatos da contabilidade gerencial. No entanto, pouco se sabe sobre os fatores que condicionam tal estruturação". Para apresentar sua agenda de pesquisa, o argumento de Macohon e Lavarda (2015) é construído em torno de: (a) apresentar a teoria da estruturação de Giddens, por meio de noções centrais, diferenciação de sistemas sociais e estruturas sociais; subconjunto das estruturas; (b) apresentar investigações que analisam a contabilidade como: 1) estrutura de significação, lentes perceptiva e constitutiva; 2) estrutura de legitimação, dispositivos window-dressing e de sanção; 3) estrutura de dominação, recursos para dominação e mecanismo ideológico. Mostram que pesquisas nacionais não focaram a estrutura de legitimação e nem os mecanismos ideológicos da estrutura de dominação; (c) destacar como a contabilidade é concebida por meio destas estruturas e sugerir que pesquisas futuras podem preencher as lacunas existentes, investigando em relação à: i) estrutura de significação, as funções, atividades e comunicação da contabilidade gerencial e/ou controladoria; ii) estrutura de legitimação, as obrigações, mecanismos de sanção, comportamentos legitimados e produção de moralidade da contabilidade e/ou controladoria em relação a outros setores da organização; iii) estrutura de dominação, os recursos autoritários e alocativos, facilidades, relações sociais e poder (MACOHON; LAVARDA, 2015).

Os achados apresentados nas Figuras 4 e 5 permitem afirmar que ainda há muito para se explorar dentro do escopo de contabilidade gerencial sob a perspectiva das teorias da prática oferecidas por Pierre Bourdieu e Anthony Giddens no Brasil. Frezatti et. al. (2015) constataram que os eventos e pesquisas acadêmicas brasileiras em contabilidade gerencial recebem influência tanto da escola americana quanto da europeia no que diz respeito aos temas de pesquisa e as metodologias empregadas nas pesquisas. Além disso, a contabilidade gerencial brasileira ainda é recente e carece de pluralidade.

Neste sentido, considerando os temas de pesquisa relacionados por Frezatti et. al. (2015), alguns dos temas potenciais que poderiam ser explorados sob as teorias de Bourdieu ou 
Giddens no contexto brasileiro são: sistemas de custos, sistemas de remuneração, avaliação de desempenho, controle gerencial, controle e cultura brasileira, gestão pública, inovação, gerenciamento de resultados, contabilidade gerencial estratégica, julgamento e tomada de decisões, accountability. Olhar esses temas sob a perspectiva da prática social oferecida por Bourdieu ou Giddens implica reconhecer e investigar, por exemplo, (i) como os aspectos inerentes à cultura brasileira e à cultura das organizações em análise se apresentam na formação do habitus e das práticas sociais; (ii) como o papel do agente e as relações de poder nas organizações contribuem para os projetos de sistemas de contabilidade gerencial; (iii) como os desdobramentos em torno de conflitos e/ou dominação nas organizações permitem compreender como a agência humana facilita ou inibe a presença de determinados elementos de controle no design organizacional; (iv) como, em determinados ambientes organizacionais, as práticas sociais de controle gerencial são produzidas e reproduzidas; (v) como as estruturas de legitimação e dominação são instituídas historicamente e como essa constituição impacta o controle gerencial e os sistemas contábeis. As constatações dessa seção sugerem que há inúmeras oportunidades abertas à exploração de pesquisadores em contabilidade gerencial no Brasil, por meio da lente desses dois teóricos da prática.

\section{Considerações Finais}

Procuramos no presente ensaio teórico-bibliográfico apresentar aos revisitar possibilidades de pesquisas dos fenômenos contábeis gerenciais no Brasil a partir da lente de dois teóricos da prática, Anthony Giddens e Pierre Bourdieu. Considerando a multiplicidade de possibilidades para abordagem de pesquisa sob a perspectiva de práticas sociais, optou-se por situar Giddens e Bourdieu dentro das escolas de prática, discorrendo, inicialmente, sobre as influências teóricas que formataram a prática social e mostrando porque estes teóricos são considerados como teóricos ligados às tradições críticas e interpretativas de pesquisa em contabilidade (WICKRAMASINGHE; ALWATTAGE, 2018).

Um dos grandes desafios para pesquisadores em contabilidade gerencial tem sido oferecer pesquisas que consistam em uma aproximação efetiva da prática, ou seja, pesquisas relevantes e de certa forma intervencionistas (SCAPENS, 2008). Uma forma de contribuir para a prática pode se dar a partir do entendimento de como ela funciona de fato nas organizações, que elementos estão envolvidos nas dinâmicas particulares das organizações e como se dão as construções sociais da prática nesses ambientes.

A partir dessa orientação, o artigo sintetizou os modos possíveis de pesquisadores se engajarem com a prática social em pesquisa. A discussão não foi plenamente aprofundada porque foge ao escopo do artigo porém, ao apresentar aos pesquisadores em contabilidade gerencial as possibilidades de engajamento com práticas em suas pesquisas, considerando as três dimensões da prática - i) prática como um fenômeno desenvolverá pesquisas que focam o que os profissionais fazem; ii) prática como uma perspectiva desenvolverá pesquisas que focam fenômenos sociais específicos; iii) prática como uma filosofia desenvolverá pesquisas que focam o entendimento de toda a realidade social -, o artigo permite reflexões de ordem epistemológicas e metodológicas imbricadas nestas perspectivas e que podem contribuir para que pesquisadores em contabilidade gerencial, e em outras temáticas contábeis, desenvolvam pesquisas relevantes para e no Brasil.

Depois de apresentar os elementos centrais das teorias de Giddens e Bourdieu, nós discorremos sobre como algumas investigações empíricas em contabilidade no Brasil têm se apropriado das teorias desses teóricos, e mostra que, no Brasil, estes teóricos ainda são subutilizados e há espaço de pesquisa para que as contribuições teóricas destes autores sejam discutidas com maior profundidade no âmbito da contabilidade gerencial. Tais discussões 
poderiam considerar uma gama de objetos de estudo como, por exemplo, agência, controle gerencial, mudanças nos sistemas contábeis, sistemas de medição de desempenho e remuneração, gestão pública.

A escolha do objeto de pesquisa poderá se beneficiar de ambas as teorias e a opção por uma delas requer que o pesquisador considere suas diferenças, conciliáveis ou não. Em outras palavras, enquanto para Giddens a agência humana "deriva mais das capacidades das pessoas e competência social do que de motivação consciente e auto interessada" (PRASAD, 2005), para Bourdieu a agência humana não é tão livre como se supõe e está limitada em função do poder das restrições culturais. Assim, ao escolher um dos teóricos para estudar agência, pesquisadores em contabilidade gerencial devem estar cônscios desta escolha e serem aptos a elaborar uma pesquisa condizente com os aspectos teóricos, epistemológicos e metodológicos derivados de sua escolha, alinhados à cada tradição de pesquisa (ROSLANDER, 2018)

Para discutir contabilidade gerencial sob a teoria de Bourdieu, pesquisadores deveriam considerar os aspectos destacados por Prasad (2005) para pesquisas que queiram adotar uma tradição praxeológica: a esfera simbólica, a reflexividade e os vieses de pesquisa e a análise relacional. Nesse sentido, a pesquisa poderia, por exemplo, evidenciar 'o mundo simbólico' da contabilidade gerencial e mostrar as estratégias de interesses ocultos por trás de grupos ou agentes nas organizações, como discorre Bourdieu (1990, 1996). Assim, segundo Everett (2018, p. 118-120), surgem como potenciais temáticas de pesquisa a associação entre capital cultural e capital econômico dentre elites, o que recebeu pouca atenção em contabilidade; regulação e estabelecimento de padrões contábeis; a representação do contador em formas culturais de expressão popular; ou no caso de violação de direitos humanos ou trabalhistas, por exemplo.

Prasad (2005) também recomenda que pesquisas que queiram adotar uma tradição estruturalista devam considerar 'a manutenção estável de um foco processual sobre todos os fenômenos sociais', de forma que, para discutir a contabilidade gerencial, pesquisadores deveriam se familiarizar com a dupla hermenêutica e analisar sociedade ou cultura em processo de elaboração. Assim, a contabilidade deve ser compreendida como aquilo que os agentes fazem em nome da contabilidade enquanto uma instituição, mas o seu produto é o resultado da dualidade e, portanto, uma ação em andamento; quando as pessoas fazem contabilidade, elas sustentam-se tanto sobre a consciência humana quanto nas estruturas de uma forma dialética e, desse modo, efetuando a construção social da realidade (WICKRAMASINGHE; ALWATTAGE, 2018, p.29).

Há que se considerar também que como toda teoria, as propostas teóricas de Giddens e Bourdieu não estão isentas de desafios e limitações empíricas e/ou críticas ontológicas. Resistências à teoria de Bourdieu, por exemplo, surgem a partir de partidários do individualismo metodológico e de correntes convencionais da teoria da ação e correntes evolucionistas das sociedades. Aqueles que consideram os fenômenos sociais resultantes de escolhas racionais e não aceitam seu "determinismo social", consequentemente, não aceitam os conceitos de habitus e campo propostos por Bourdieu (THIRY-CHERQUES, 2006).

Pozzebon e Pinsonneault (2005) discorrem que, embora a teoria da estruturação seja um marco importante para compreender a organização e a gestão, ela possui dois importantes desafios: i) operacionalizar a complexidade dos conceitos, proposições e o alto grau de abstração; ii) dificuldade para acoplar à teoria a qualquer abordagem metodológica. $\mathrm{O}$ trabalho destas autoras se propõe a contribuir com diretrizes concretas de aplicação metodológica da teoria da estruturação a partir de pesquisas empíricas na área de tecnologia da informação. Whittington (2010) igualmente reconhece a dificuldade de aplicação empírica dos conceitos de Giddens e oferece uma revisão de operacionalizações empíricas da teoria da estruturação na literatura gerencial. 
Por fim, cabe destacar que as possibilidades teóricas e metodológicas apontadas no presente ensaio consistem em um 'convite' aos pesquisadores em contabilidade gerencial para dar um passo além daquele que é oferecido pela tradição de pesquisa mainstream, geralmente apoiadas em abordagens positivistas ou pós-positivistas, e considerar as perspectivas de pesquisas de tradição interpretativas e crítica que adotam as teorias sociais para explorar as construções práticas no mundo organizacional. Assim, nós entendemos que uma abordagem aos problemas de contabilidade gerencial a partir das teorias da prática social oferecidas por Giddens ou Bourdieu permitirão uma compreensão dos processos sociais de forma mais ampla e aprofundada, pois evidenciarão, por exemplo, como ocorrem as interações estruturais de significação, legitimação e dominação, e como as relações de poder e as lutas por capitais dentro das organizações impactam o desenho e o uso dos sistemas de controle gerencial.

Nós também reconhecemos, em concordância com Scapens (2008), Modell (2015), Frezatti et al. (2015), Lourenço e Sauerbronn (2016; 2017), que a pluralidade de teorias e metodologias bem como o debate junto aos pares podem contribuir significativamente para o desenvolvimento da contabilidade gerencial no Brasil. A nossa discussão apresentou apenas uma pequena fatia do que se tem produzido em contabilidade sobre Pierre Bourdieu e Anthony Giddens no Brasil, visto que reunimos publicações selecionadas de poucas bases da área contábil sem contemplar a amplitude das pesquisas presentes na área de estudos organizacionais, que tem uma trajetória de pesquisa bem desenvolvida com fundamentação nestes dois autores. No entanto, esperamos que o artigo motive pesquisadores em contabilidade gerencial a adentrarem no campo de pesquisa para desenvolverem investigações a partir das concepções destes teóricos da prática social reconhecendo seus potenciais e limitações.

\section{Referências}

AHRENS, T.; CHAPMAN, C. S. Theorizing Practice in Management Accounting Research. In: CHAPMAN, C. S.; HOPWOOD, A. G.; SHIELDS, M. D. Handbook of Management Accounting Research. Oxford: Elsevier, v. 1, p. 99-112, 2007.

ANAND, N.; JONES, B. C. Tournament Rituals, Category Dynamics, and Field Configuration: The Case of the Booker Prize. Journal of Management Studies, v. 45, n. 6, p. 1036-1060, 2008. DOI/10.1111/j.1467-6486.2008.00782.x

BAKER, C. R.; BETTNER, M. S. Interpretive and critical research in accounting a commentary on its absence from mainstream accounting research. Critical Perspectives on Accounting, v. 8, p. 193-310, 1997. DOI: 10.1006/cpac.1996.0116

BAXTER, J.; CHUA, W. F. Alternative management accounting research - whence and whither. Accounting, Organizations and Society, v. 28, p. 97-126, 2003. DOI:10.1016/S0361-3682(02)00022-3

BAXTER, J.; CHUA, W. F. Be(com)ing the chief financial officer of an organisation: Experimenting with Bourdieu's practice theory. Management Accounting Research, v. 19 p. 212-230, 2008. DOI:10.1016/j.mar.2008.06.001

BEUREN, I. M.; ALMEIDA, D. M. Impactos da implantação das normas internacionais de contabilidade na controladoria: um estudo à luz da teoria da estruturação em uma empresa têxtil. R.Adm., v. 47, n. 4, p. 653-670, 2012. DOI: 10.5700/rausp1065 
BEUREN, I. M.; ALMEIDA, D. M. Impacto da Adoção das Normas Internacionais de Contabilidade na Área da Controladoria / Impact of the Adoption of International Accounting Standards in the Area of Controllership. Revista de Administração Contemporânea, v. 19, n. 3, p. 311-335, 2015. DOI: 10.1590/1982-7849rac20151704

BISPO, M. Estudos Baseados em Prática: Conceitos, História e Perspectivas. RIGS revista interdisciplinar de gestão social, v. 1, n. 1, p. 13-34, 2013.

BOURDIEU, P. Esboço de uma teoria da prática. In: ORTIZ, R. Pierre Bourdieu: Sociologia. São Paulo: Ática, 1983. p. 46-81.

BOURDIEU, P. Distinction: A social Critique of the Judgement of Taste. Cambridge, Massachusetts: Harvard University Press, 1984.

BOURDIEU, P. Structures, Habitus, Practices. In: BOURDIEU, P. The Logic of Practice. Redwood City: Stanford University Press, 1990. p. 52-65.

BOURDIEU, P. Razões práticas: sobre a teoria da ação. Campinas: Papirus, 1996.

BOURDIEU, P. La Lógica de los Campos. In: BOURDIEU, P.; WACQUANT, L. Una invitación a la sociología reflexiva. Buenos Aires: Siglo XXI Editores, 2005. p. 147-172.

BUSCO, C.; SCAPENS, R. W. Management accounting systems and organisational culture. Qualitative Research in Accounting \& Management, v. 8, n. 4, p. 320-357, 2011. DOI: $10.1108 / 11766091111189873$

COAD, A. F.; HERBERT, I. P. Back to the future: new potential for structuration theory in management accounting research?. Management Accounting Research, v. 20, n. 3, p. 177192, 2009. DOI:10.1016/j.mar.2009.02.001

COORDENAÇÃO DE APERFEIÇOAMENTO DE PESSOAL DE NÍVEL SUPERIOR (CAPES). Avaliação da CAPES aponta crescimento da pós-graduação brasileira: Resultado por Área de Avaliação. Brasília, 2017. Disponível em: http://www.capes.gov.br/sala-de-imprensa/noticias/8558-avaliacao-da-capes-apontacrescimento-da-pos-graduacao-brasileira. Acesso em: 14/10/2017.

CHIAPELLO, E.; BAKER, C. R. The introduction of French theory into English language accounting research. Accounting, Auditing \& Accountability Journal, v. 24, n. 2, p. 140160, 2011. DOI: 10.1108/09513571111100663

COOPER, D. J.; HOPPER, T. Critical Theorising in Management Accounting Research. In: CHAPMAN, C. S.; HOPWOOD, A. G.; SHIELDS, M. D. Handbook of Management Accounting Research. Oxford: Elsevier, 2007. p. 207-245.

ENGLUND, H.; GERDIN, J., BURNS, J. "25 Years of Giddens in accounting research: achievements, limitations and the future," Accounting, Organizations and Society, v. 36, n. 8, p. 494-513, 2011. DOI:10.1016/j.aos.2011.10.001 
EVERETT, J. Bourdieu. In: Roslender, R. (org.) The Routledge Companion to Critical Accounting. New York: Routledge, Cap. 7, 2018.

FREZATTI, F. et al. A pesquisa em contabilidade gerencial no Brasil: Desenvolvimento, dificuldades, e oportunidades. Revista Universo Contábil, v. 11, n. 1, p. 47-68, 2015. DOI:10.4270/RUC.2015103

GIDDENS, A. Elements of the Theory Structuration. In: GIDDENS, A. The Constitution of Society: Outline of the Theory of Structuration. Berkeley and Los Angeles: University of California Press, 1984. p. 1-39.

GIDDENS, A.; SUTTON, P. W. Conceitos Essenciais da Sociologia. São Paulo: Editora Unesp, 2016.

GOLSORKHI, D. et al. Introduction: What is Strategy as Practice? In: GOLSORKHI, D., et al. Cambridge Handbook of Strategy as Practice. Cambridge: Cambridge University Press, 2010.

HESFORD, J. W. et al. Management Accounting: A Bibliographic Study. In: CHAPMAN, C. S.; HOPWOOD, A. G.; SHIELDS, M. D. Handbook of Management Accounting Research. Oxford: Elsevier, 2007. p. 3-26.

HOMERO Jr, P. F. A Constituição do Campo Científico e a Baixa Diversidade da Pesquisa Contábil Brasileira. Revista de Educação e Pesquisa em Contabilidade, v. 11, n. 3, p. 314328, 2017a. DOI: /10.17524/repec.v11i3.1565

HOMERO Jr, P. F. O Complexo de Vira-Lata no Discurso Acadêmico Brasileiro sobre as IFRS. Sociedade, Contabilidade e Gestão, Rio de Janeiro, v. 12, n. 2, mai/ago 2017b.

JAYASINGHE, K.; WICKRAMASINGHE, D. Power over empowerment: Encountering development accounting in a Sri Lankan fishing village. Critical Perspectives on Accounting, v. 22, p. 396-414, 2011. DOI: 10.1016/j.cpa.2010.12.008

LAUGHLIN, R. Methodological themes Empirical research in accounting: alternative approaches and a case for "middle-range" thinking. Accounting, Auditing \& Accountability Journal, v. 8, n. 1, p. 63-87, 1995.

LAVARDA, C. E. F.; BARRACHINA, M.; FELIU, V. M. R. Paradigmas de investigación en contabilidad de gestión. Revista de Contabilidade do Mestrado em Ciências Contábeis da UERJ, Rio de Janeiro, v. 13, n. 1, p. 1-18, 2008.

LOURENÇO, R. L.; SAUERBRONN, F. F. Revistando possibilidades epistemológicas em contabilidade gerencial: em busca de contribuições de abordagens interpretativas e críticas no Brasil. Revista Contemporânea de Contabilidade, v. 13, n. 28, p. 101-124, 2016. DOI: 10.5007/2175-8069.2016v13n28p99

LOURENÇO, R. L.; SAUERBRONN, F. F. Uso da Teoria de Agência em Pesquisas de Contabilidade Gerencial: Premissas, limitações e formulações alternativas aos seus 
pressupostos. Advances in Scientific and Applied Accounting, v. 10, n. 2, p. 153-171, 2017. DOI: $10.14392 /$ asaa.2017100202

LUFT, J.; SHIELDS, M. D. Mapping Management Accounting: Graphics and Guidelines for Theory-Consistent Empirical Research. In: CHAPMAN, C. S.; HOPWOOD, A. G.; SHIELDS, M. D. Handbook of Management Accounting Research. Oxford: Elsevier, 2007. p. 27-98.

MACIEL, C. D. O.; AUGUSTO, P. O. M. A practice turn e o movimento social da estratégia como prática: está completa essa virada? RAM, REV. ADM. MACKENZIE, São Paulo, v. 14, n. 2, p. 155-178, 2013. DOI: 10.1590/S1678-69712013000200007

MARTINS, G. A.; ZANCHET, A. (2012). Sobre a Complexidade dos Achados de Pesquisas Contábeis. II Colóquio Internacional de Epistemologia e Ciência da Administração, Florianópolis, SC, Brasil.

MACOHON, E. R.; LAVARDA, C. E. F. A Tríade de Giddens na Pesquisa em Contabilidade. Revista de Educação e Pesquisa em Contabilidade (REPeC), v. 9, n. 3, p. 242-257, 2015. DOI: $10.17524 /$ repec.v9i3.1192

MALSCH, B.; GENDRON, Y.; GRAZZINI, F. Investigating interdisciplinary translations: the influence of Pierre Bourdieu on accounting literature. Accounting, Auditing \& Accountability Journal, v. 24, n. 2, p. 194-228, 2011. DOI: 10.1108/09513571111100681

MODELL, S. Theoretical triangulation and pluralism in accounting research: a critical realist critique. Accounting, Auditing \& Accountability Journal, v. 28, n. 7, p. 1138 - 1150, 2015. DOI: 10.1108/AAAJ-10-2014-1841

NICOLINI, D. Praxeology and the Work of Giddens and Bourdieu. In: NICOLINI, D. Practice Theory, Work and Organization: An Introduction. Oxford, United Kingdom: Oxford University Press, 2012. p. 44-76.

NICOLINI, D. Praxis and Practice Theory: A Brief Historical Overview. In: NICOLINI, D. Practice Theory, Work, \& Organization: An introduction. New York: Oxford University Press, 2012a. p. 23-43.

ORLIKOWSKI, W. J. Practice in research: phenomenon, perspective and philosophy. In: GOLSORKHI, D., et al. Cambridge Handbook of Strategy as Practice. New York: Cambridge University Press, 2010. p. 23-33.

ORTIZ, R. A procura de uma sociologia da prática. In: ORTIZ, R. Pierre Bourdieu: Sociologia. São Paulo: Atica, v. Coleção Grandes Cientistas Sociais, 1983, p. 7-36.

POZZEBON, M.; PINSONNEAULT, A. Challenges in Conducting Empirical Work Using Structuration Theory: Learning from IT Research. Organization Studies, v. 26, n. 9, p. 13531376, 2005. DOI: $10.1177 / 0170840605054621$

PRASAD, P. Structuration and Praxeology: Transcending Dualism Within Frameworks of Power. In: PRASAD, P. Crafting Qualitative Research: Working in the postpositivist traditions. New York: M.E.Sharpe, 2005. p. 183-209. 
QUEIROZ, V. D. S. The good, the bad and the ugly: estudo sobre pequenas e médias empresas familiares brasileiras a partir da teoria da ação de Pierre Bourdieu. Cadernos EBAPE.br, v. 6, n. 1, p. 1-17, 2008.

RECKWITZ, A. Toward a Theory of Social Practices: A Development in Culturalist Theorizing. European Journal of Social Theory, v. 5, n. 2, p. 243-263, 2002.

RICCIO, E. L.; MENDONÇA NETO, O. R.; SAKATA, M. C. G. Movimentos de teorias em campos interdisciplinares: a inserção de Michel Foucault na contabilidade. Revista de Administração Contemporânea, v. 11, n. SPE2, p. 11-32, 2007. DOI: 10.1590/S141565552007000600002 .

ROSLENDER, R. Introduction. Chapter 1. In: ROSLENDER, R. The Routledge Companion to Critical Accounting. New YorK: Routledge, 2018.

RYAN, B.; SCAPENS, R. W.; THEOBALD, M. Traditions of research in management accounting. In: RYAN, B.; SCAPENS, R. W.; THEOBALD, M. Research Method and Methodology in Finance and Accounting. London: Wouth Wester: Cengage Learning, 2002. p. 68-93.

SANTOS, J. M; GONÇALVES, G. Ética da Comunicação Governamental. In: M. C. Patrão Neves \& R. Sampaio (ed.), Ética aplicada - Comunicação Social. Lisboa: Edições 70, 2017.

SAUERBRONN, F. F.; FARIA, A. A. Agência em estratégia: conectando prática social e codeterminação. RAM, Rev. Adm. Mackenzie, v. 12, n. 6, Edição Especial, 2011.

SCAPENS, R. W. Seeking the relevance of interpretive research: A contribution to the polyphonic debate. Critical Perspectives on Accounting, v. 19, p. 915-919, 2008.

SIEWEKE, J. Pierre Bourdieu in management and organization studies - A citation context analysis and discussion of contributions. Scandinavian Journal of Management, v. 30, p. 532-543, 2014. DOI: 10.1016/j.scaman.2014.04.004

SILBERMAN, I. M.; PACHECO, L. O.; FONSECA, A. C. P. D. D. Relações de Poder e Legitimidade dos Produtos Vendidos nas Feiras Orgânicas do Rio de Janeiro: Uma Análise Crítica à Luz da Teoria do Poder Simbólico de Bourdieu e da Escola Estratégica de Poder de Mintzberg. Sociedade, Contabilidade e Gestão, Rio de Janeiro, v. 10, n. 3, p. 118-138, 2015.

THEÓPHILO, C. R.; IUDÍCIBUS, S. D. Uma análise crítico-epistemológica da produção científica em contabilidade no Brasil. Contabilidade, Gestão e Governança, v. 8, n. 2, p. 147 $175,2009$.

THIRY-CHERQUES, H. R. Pierre Bourdieu: a teoria na prática. Revista de Administração Pública, v. 40, n. 1, p. 27-53, 2006. DOI: 10.1590/S0034-76122006000100003.

TOWNLEY, B. Bourdieu and Organizational Theory: A Ghostly Aparition? In: ADLER, P. et al. (Eds.). The Oxford Handbook of Sociology, Social Theory, and Organization Studies: Contemporary Currents. Oxford: Oxford University Press, 2014. p. 39-63. 
WANDERLEY, C. D. A.; CULLEN, J. Management Accounting Research: Mainstream versus Alternative Approaches. Revista Contabilidade Vista \& Revista, v. 22, n. 4, p.15-44, 2011.

WANDERLEY, C. D. A.; CULLEN, J. Um Caso de Mudança na Contabilidade Gerencial: a Dinâmica Política e Social*/A Case of Management Accounting Change: the Political and Social Dynamics. Revista Contabilidade \& Finanças, v. 23, n. 60, p. 161-172, 2012.

WHITTINGTON, R. Giddens, structuration theory and strategy as practice. In: GOLSORKHI, D., et al. Cambridge handbook of strategy as practice. Cambridge: Cambridge University Press, 2010. p. 109-126.

WICKRAMASINGH, D.; ALWATTAGE, C. Interpretivism. In: Roslender, R. (org.) The Routledge Companion to Critical Accounting. New York: Routledge, Cap. 2, 2018.

\footnotetext{
i Segundo Santos e Gonçalves (2017, p. 9), a "sabedoria prática política" é a phronêsis do governante, uma sabedoria prática especializada, como a sabedoria de um juiz (a juris-prudência) ou de um político que é, sem dúvida, uma virtude da inteligência, mas que regulam o uso das virtudes éticas.
} 